\title{
Award errors and permanent disability benefits in Spain*
}

\author{
Sergi Jiménez-Martín ${ }^{\dagger} \quad$ José M. Labeaga ${ }^{\ddagger} \quad$ Cristina Vilaplana Prieto ${ }^{\S}$
}

May 31, 2006

\begin{abstract}
There is a controversial debate about the effects of permanent disability benefits on labor market behavior. In this paper we estimate equations for deserving and receiving disability benefits to evaluate the award error as the difference in the probability of receiving and deserving using survey data from Spain. Our results indicate that individuals aged between 55 and 59, self-employers or working in an agricultural sector have a probability of receiving a benefit without deserving it significantly higher than the rest of individuals. We also find evidence of gender discrimination since male have a significantly higher probability of receiving a benefit without deserving it. This seems to confirm that disability benefits are being used as an instrument for exiting the labor market for some individuals approaching the early retirement or those who do not have right to retire early. Taking into account that awarding process depends on Social Security Provincial Department, this means that some departments are applying loosely the disability requirements for granting disability benefits.
\end{abstract}

JEL CODES: H55, J26

KEYWORDS: DISABILITY BENEFITS, AWARD ERROR, EARLY RETIREMENT, SOCIAL SECURITY

*Financial help from Fundación BBVA and projects BEC2002-04294-C02 and SEJ2005-08793-C04-01/04 are gratefully acknowledged. We thank Hugo Benitez-Silva and workshop and conference participants at UC3M, UPF, EEA (Amsterdam), and UPO (Sevilla) for helpful comments.

${ }^{\dagger}$ Universitat Pompeu Fabra, Barcelona

${ }^{\ddagger}$ FEDEA and UNED, Madrid

${ }^{\S}$ Universidad Católica San Antonio de Murcia 


\section{Introduction}

There is a controversial debate about the effects of permanent disability benefits on labor market behavior. Parsons and Slade (1980) attribute most of the decrease in the participation of the workforce to the increasing generosity of disability benefits. Leonard (1979) also finds that repercussions over labor market are considerable, whereas Haveman and Wolfe (1984a, b), Bound (1989) and Haveman et al., (1991) support that the impact is much more limited. Other factors like spouse contributions to family income, the disappearance of the stigma associated with early retirement and more generous early retirement benefits may explain the decline in labor participation of older workers.

In this paper we study permanent disability benefits award policy concession in Spain in order to evaluate award errors and policies using data from the Disabilities, Deficiencies and Health Status Survey (DDHSS). In a context of an ageing population and increasing shortage of labor supply this can be specially rellevant in many developed countries, including Spain. In order to reverse these trends and get more work out of the near elderly $(50+)$ individuals, it is important to understand the factors (either socioeconomic or health related) and policies behind benefit concession policies and award errors.

Disability benefits in many European countries are due to "truly" medical reasons, to economic reasons and/or the combination of these two factors. One of the objectives of this exercise is to tentatively distinguish between them. For example, those in sample receiving a disability benefits which do not have any disability can be classified as receiving a benefit dut to "economic reasons". Alternatively those receiving a benefit having some disabilities but of limited importance can be classified as receiving a benefit due to the combination of disabilities and economic reasons or policies. We put special emphasis in the detection of two major redistributive policies: firstly, a policy easing transitions to inactivity of older individuals; and, secondly, a policy favoring transitions to inactivity of workers in the less favored regions and thus transferring income from rich to poor regions. These policies are specially important in the Spanish case since disability benefits are, ceteris paribus, more generous and better treated fiscally than other benefits. Regarding the first policy mentioned, it is well known that permanent disability benefits have been intensively used in Europe to ease transitions to retirement before the early retirement age (see the collection of papers in Gruber and Wise (1999) for illustrations for eleven countries) and Spain is not an exception. We center the analysis on individuals aged 50-64 because of for them the effect of this policy is much more evident. To illustrate the second policy we present in Table C.1 (appendix C) the recent trends of the ratio of disability to retirement benefits by region. It is evident the great disparity of this ratio across Spanish regions. Thus, it becomes clear the need to audit Social Security awarding process of permanent disability benefits to determine what kind of social, political or administrative factors are responsible for the divergences observed.

While there are empirical studies in some countries providing evidence about disability benefits (for the US see, for instance, Bound, 1991; Kreider, 1991; Benítez-Silva et al., 2004 and 2005; Bound et al., 1999 using the Health and Retirement Survey), the lack of adequate data explains the absence of studies of this kind in Spain. ${ }^{1}$, The recent disposal of the Disabilities, Deficiencies and Health Status Survey (DDHSS from now on) carried out by the Spanish National Bureau of Statistics in 1999, whose results have recently been published, make it possible to conduct such an study in Spain.

According to the Social Security Law (Art. 136) an individual deserves a benefit if "after having received the prescribed treatment, presents anatomical or functional serious reductions, capable of objective and predictably definitive determination, that diminish or eliminates his la-

\footnotetext{
${ }^{1}$ For other European countries work is also limited. For details and evidence about disability in some European countries, including Spain, see the collection of papers in Gruber and Wise (1999)
} 
bor capacity". Thus, it turns out that the fundamental issue is to have a precise and trustworthy measure of what is understood by deserving a disability benefit. The idea that lies behind the concept of disability is not exempt from a high degree of subjectivity. Many studies have used self-reported health and disability measures (Boskin and Hurd, 1978; Gordon and Blinder, 1980; Hanoch and Honig, 1983; Berkovec and Stern, 1991). Others have argued that these indicators are not appropriate for measuring working limitations (Zabalza et al., 1980; Chirikos and Nestel, 1984; Bazzoli, 1985; Bound, 1991; Bound et al., 1995; Bound and Burkhauser, 1999). The most common view is that some survey respondents may inflate the incidence and severity of health problems in order to increase the probability of receiving a disability benefit (Burkhauser, 1979; Parsons, 1980 ; Anderson and Burkhauser, 1985; Kerkhofs and Lindeboom, 1995). On the other hand, Stern (1989), Dwyer and Mitchell (1999) and Benítez-Silva et al., (2004 and 2005) conclude that self-reported measures are reasonable indicators of health status.

One of the main contributions of this paper is the design of a disability indicator that measures if an individual deserves a permanent disability benefit. In the Disabilities Questionnaire from the DDHSS, respondents are required to enumerate all disabilities suffered according to a established classification of 36 disabilities. Fixing a threshold of severity and expected evolution of the disability, it is possible to determine whether an individual deserves a disability benefit. For this purpose, we have adopted the definition of what the Social Security understands for permanent disability, and used it as an standard according to which individuals determine their level of disability. Although we agree that some individuals have incentives to misreport their disability status and to exaggerate health problems when applying for a benefit, these incentives disappear when answering a survey in which confidentiality is guaranteed. Indeed, in the survey that we are going to use, $48.75 \%$ of men and $33.92 \%$ of women who receive a disability benefit declare not to suffer any disability. We have proposed six disability indicators and have performed exogeneity, consistency and unbiased individuals' disability evaluation tests to guarantee that the surviving indicator represents best the criteria applied by Social Security Administration.

Our results are related with those of Benítez-Silva et al. (2004, 2005), who compare objective, official data on disability with self-reports. In this paper, under the assumption that the official data are correct, the hypothesis that self-assessed health is an unbiased indicator of the disability insurance award decisions cannot be rejected. On the other hand, Baker et al. (2004) have come to a rather different result, where self-reported measures, i.e., survey reports on chronic ailments are measured with considerable error compared to medical reports.

To measure the award error we compare two variables: the Social Security awarding decision, and the deserving indicator designed according to the legal text. The latter variable can be interpreted as the Social Security decision with perfect information and without any policy consideration. ${ }^{2}$ Using information for a set of individuals about whether they receive a disability benefit, and introducing the disability criteria to determine if they deserve or not, we can estimate the joint distribution of the variables receiving and deserving, from which an award error can be derived. It is convenient to note that the award error is not the same than the error type II. The first refers to the probability of not deserving a benefit conditioned to receiving it, and the second refers to the probability of receiving a benefit conditioned to not being disabled.

Our results indicate that individuals aged between 55 and 59, self-employed or working in an agricultural sector have a probability of receiving a benefit without deserving it significantly higher than the rest of individuals. This seems to confirm that disability benefits are being used as an instrument for exiting the labor market for those who do not wish to wait until the early retirement and face the age penalties, or those who do not have right to early retirement

\footnotetext{
${ }^{2}$ We face a situation of asymmetric information with a completely informed principal (the individual) and an agent with incomplete information (the Social Security). The existence of hard-to-diagnose conditions may make it much more difficult for Social Security to tag those unable for work from those that are able bodied because of the imperfect information about the nature of the disability, generating a moral hazard problem.
} 
because are affiliated to special regimes (see Boldrin et al, 1999 for a description of Social security rules and regimes). We also find significant regional differences in the probability of receiving (again, see Boldrin et al., 1999, for preliminar evidence). Taking into account that awarding process depends on Social Security Provincial Department, this means that some departments are applying loosely the disability requirements for granting disability benefits.

The structure of the paper is as follows. In section 2 we explain briefly the characteristics of the Spanish disability system, we review literature of disability measures and design our deserving disability benefit indicator. The economic and econometric setup for the analysis is presented in section 3. Also in this section we describe the data and perform several specification diagnostics. In section 4 we present the main estimation results. In section 5 we propose an alternative mechanism for awarding disability benefits. Finally, in section 6 we conclude with some policy implications.

\section{Disability in Spain: concept, benefits, and measurement.}

\subsection{Concept of disability}

Permanent disability is the situation of a worker that, after going through the prescribed treatment and being released from medical care, still presents serious anatomical or functional reductions, susceptible to objective determination and predictably permanent, that diminish or impede their ability to work. The possibility of eventually recovering the ability to work will not be an obstacle to this classification if such a possibility is estimated as uncertain or very long term by a medical team.

A worker's anatomical or functional reductions that exist prior to his or her affiliation with the Social Security will not impede the classification of his or her situation as permanent disability, in the case of disabled people whose conditions have worsened after their affiliation, causing by themselves or due to the occurrence of new lesions or pathologies a decrease or annulment of the working capacity they had at the time of their affiliation. Medical records will not be necessary to assess permanent disability if there are permanent after-effects.

The disability situation may be reviewed due to worsening, improvement, or misdiagnosis of the condition, or due to carrying out work while the disabled person is still under 65 years of age. It can lead to the confirmation or modification of the degree of the disability, or the termination of the disability consideration, and therefore, of the disability benefits.

\section{Disability benefits}

The Spanish Social Security system provides insurance against both temporary and permanent illness or disability.

Temporary illness or disability The terms of provision of the subsidy for temporary illness or disability (incapacidad laboral transitoria) has undergone frequent changes. Eligibility requires affiliation to the system for a minimum period that depends upon the nature of the covered risk. Common illness requires only 180 days of contributions during the last 5 years, whereas no minimum eligibility criterion is imposed for work-related accidents or illnesses.

The benefit base depends on actual earnings during the last 12 months. In case of common illness or work-unrelated accident, the subsidy is equal to 60 percent of the benefit base for each day of absence between the 4 -th and the 20 -th, and to 75 percent thereafter until the maximum period (18 months) is reached. After this period the worker must either return to work or, conditional on passing a medical examination, be classified as "permanently disabled". 
Contributive disability pensions Contributory disability benefits (DI) are far more generous than any other old-age program, since they are not subject to penalties for young age or insufficient years of contribution. DI benefits are subject to approval by a medical examiner (notoriously, the tightness of the admissibility criteria used by examiners varies both over time and across regions) and, since the early 1990s, they have become harder to obtain at older ages [see Boldrin et al (1999) for further details]. ${ }^{3}$

Disability pensions are distinguished into contributory and non-contributory. They are converted into retirement pensions once the beneficiaries turn 65 years of age, but keeping a very favorable tax treatment. Eligibility and pension amounts depend on the level of disability. The 1985 reform distinguished four levels of permanent disability characterized by increasing severity. Since then, the legislation has formally reduced them to three, but it has also created a special subcase of the first level with the explicit purpose of using the disability funds to subsidize the dismissal of old workers from certain sectors or geographical areas. The first level (incapacidad permanente total para la profesión habitual, or IPT) corresponds to inability to do the usual job. A special subcase (incapacidad permanente total cualificada para la profesión habitual, or IPTC) applies only to employees older than 55 which are in particular socioeconomic situations. The second level (incapacidad permanente absoluta, or IPA) corresponds to inability to do any kind of job. The third level (gran invalidez, or GI) requires, in addition, continued attendance by other persons in order to carry out the basic vital functions. In terms of requirements, when disability is caused by an ordinary illness, eligibility to a pension requires from 5 to 15 years of contributions, depending on age. There is no contributive requirement when the disability is caused by an accident, whether or not work-related, or a professional illness.

The benefit base depends on the source of disability. In case of ordinary illness, it is computed as for old-age pensions. For work-unrelated accident, it is the average annual wage over a period of 24 consecutive months chosen by the person within the last 7 years of work. For work-related accident or professional illness, it is the average wage in the last year of work. The pension equals 55 percent of the benefit base under IPT, and increases to 75 percent under IPTC. In case of IPA, it is equal to 100 of the benefit base, whereas for GI it is equal to 100 percent of the benefit base plus another 50 percent covering the person taking care of the disabled.

\subsection{Disability measures}

Labor capacity is an important determinant of labor behavior and affects the retirement decision and the application for disability benefits. Most people argue that one of the crucial reasons for retiring before the normal age is poor health status. However, several reasons can lead us to suppose that self-reported measures are biased. Anderson and Burkhauser (1984) pointed that searching for good disability measures is one of the open questions in the study of older workers labor behavior. The true disability status is an unobservable variable, but different measures can be used to approximate it. In general, disability measures can be classified into two groups:

Objective measures: they are not based on self-reported health status and do not present, as a rule, endogeneity problems. Mortality rates, number of days of work lost because of illness or body mass index are some examples.

Subjective measures: we can distinguish between global and specific subjective measures.

\footnotetext{
${ }^{3}$ It is the responsibility of the Provincial Directorates of the INSS through the Disability Evaluation Teams and in every stage of the procedure, to declare the Permanent Disability condition so benefits may be assigned. The Provincial Directorate of the INSS will issue a resolution in a maximum of 135 days. If no resolution has been issued within this deadline, the application shall be deemed denied by way of negative administrative silence. If it is necessary to ask for a hearing or if complementary documentation is requested, the interested party will have 10 days to argue his case or present the documentation.
} 
1. Global measures are based on self-reported health status. They are normally recorded according to question like, how would you define your health status: excellent, good, regular or bad? Do you think that the quantity or quality of work you do is affected by some problem of health or disability?

Anderson and Burkhauser (1984), Bound (1991) and Waidman et al. (1995) indicated that these measures have several problems. First of all, they are based on personal judgements of health status and it is very difficult to compare answers from different individuals. Second, self-reported measures may not be independent of what we are trying to explain. The main reason is that some survey respondents may inflate the severity of their health problems in order to rationalize their relation with economic activity (p.e. unemployment).

However Benítez Silva et al. (2004, 2005) define a variable called "true disability" if the individual considers that he suffers any impairment or health problem that limits the amount of work he can do. They use this measure for identifying type I and type II errors in permanent disability benefits. Bound and Burkhauser (1999) and Bound and Waidmann (1992) criticize this definition because individuals who apply for a benefit, and those who are receiving it may have incentives to exaggerate health problems. Finally, sometimes individuals unable to continue working may apply for early retirement. Then, those with a high relative value of leisure are going to have financial incentives to identify themselves as disabled.

2. Specific measures, which are self-reported measures based on specific conditions of the individual. Cardiovascular illnesses or vertebral column deficiencies are good examples of this type of variables, which are less prone to suffer systematic errors than global subjective measures. This kind of measures can be used as indicators of health status in a participation equation (Bound et al., 1995). However, this strategy is not very common and specific measures are usually employed as instruments for global subjective measures (Stern, 1989; Bound et al., 1998). The limitation of the method proposed by Stern (1989) is that the influence of another economic variables over retirement decisions is left unidentified. The implicit assumption when using this technique is that self-reported health status is insensitive to psychological and monetary incentives.

The choice of the disability measure is very important because it may bias the results obtained (Anderson and Burkhauser, 1984). Endogeneity problems are going to overestimate the impact of health status over labor force participation, while measurement errors are going to underestimate this effect. However, these biases operate in opposite directions and controls can be implemented to obtain upper and lower thresholds for the effect of reported disability over labor behavior (Bound, 1991).

At the end, one has to consider the trade off between measurement error of objective measures, and measurement error and endogeneity problems of subjective measures. Both the objective and the subjective indicators are correlated with education, occupation and earnings. These variables are also important for explaining exit from the labor force. One interpretation for these correlations is that individuals with poor health status tend to retire earlier and that bad employment perspectives make workers leave the labor force, and afterwards they justify their exit as a decrease in labor capacity.

\subsection{Design of the disability indicator}

In this section we present several alternatives in order to determine whether an individual deserves a permanent disability benefit using the DDHSS survey defines a disability as any serious limitation that affects for more than one year the activity of the individual and that 
has its origin in a deficiency. Therefore, a respondent is considered to be not disabled if he does not have any difficulty in achieving any of 36 daily living activities (see the appendix for details). So the above definition is based on the individual's subjective perception of her own limitations. ${ }^{4}$ The concept of disability relies on the idea of deficiency as the only possible origin of the disability, that is to say, it tries to analyze if the individual is capable of performing a determined activity independently if he really practices it or not. It is also necessary to bear in mind that disabilities cannot be given alone, but the same person can be affected by two or more disabilities that can be independent among them, originated by different deficiencies or by the same one.

The Spanish legislation applies the professional disability principle to determine who deserves a benefit. This principle takes into account three factors: the set of sequels, ailments and diseases, the occupations affected by limitations, and the particular effect on each individual (Barba Mora, 2001). It is not possible to consider the second factor because we do not know the occupation for pensioners without disabilities. As regards to the third factor it is impossible to consider in a model variables such as resistance to pain and personality, which are genuinely unobservable. In order to relieve this disadvantage we are going to restrict the analysis to survey respondents from 45 to 59 years old. This means that we only require elements of pathological character. The determination of the degree needed to establish permanent disability would require very deep medical knowledge. Since we do not rely on this information, we will only look at the external symptoms of the deficiencies, i.e., we focus on disabilities. For each disability we are going to fix a threshold of severity, prognosis and origin and will assume that an individual deserves a disability benefit when passing the threshold.

In order to be as exhaustive as possible we design six different criteria for deserving a disability benefit. The definition of the various criteria used is described in Table 1. We distinguish aspects of the variable severity, evolution, or origin of the each deficiency. Each criterion is represented by a binary indicator that takes the value one it the individual satisfies the criterion and value zero otherwise. Afterwards we choose the best criterion for estimation of the model using exogeneity and consistency tests for each of the variables. We assume that individuals who have not answered the Disabilities and Deficiencies Questionnaires do not suffer any kind of health problem, so all criteria take the value zero for them.

\section{Economic and econometric Framework}

After receiving an invalidity shock the individual goes to temporary illness/invalidity benefits. The invalidity shock cause a decrease in the individual earnings potential. In particular, we consider that the wage process $w$ is shifted downwards by the health shock $\left(w_{t}=w * h_{t}, h \leq 1\right)^{5}$. The individual may recover (partially) or not but the degree of recovery is not observable to the Social Security. After exhaustion of temporary benefits, the individuals decides whether to apply or not. However, since the application process is unobservable for, we assume that all the individuals that in sample apply for a disability pension. ${ }^{6}$ If he applies for disability benefits, he may be rewarded or not, and in case of acceptance, he will receive them until death $(T)$. But if the application is rejected he has to return to work at a lower expected wage until retirement age $(\tau)$.

Then the expected income of returning to work $\left(E Y_{W}\right)$ is equal to the utility of labor earnings $(w)$ until retirement age plus retirement benefits $(R B)$ from that moment till death, where $\Upsilon$

\footnotetext{
${ }^{4}$ All disabilities are investigated even if they are overcome with the use of some technical help. See the appendix A for details.

${ }^{5}$ Spanish legislation establishes that in case of a reduction in efficiency at working place, wage may be diminished up to a $25 \%$.

${ }^{6}$ The Application process has several advantages and practically no cost.
} 
Table 1: Six alternative criterion for deserving a disability benefit

\begin{tabular}{|c|c|c|c|c|}
\hline & Criterion 1 & Criterion 2 & Criterion 3 & Criterion 4 \\
\hline Severity & $\begin{array}{l}\text { Can present one of the } \\
\text { following degrees: } \\
\text { - Serious difficulty } \\
\text { - Cannot do the } \\
\text { activity }\end{array}$ & $\begin{array}{l}\text { Same requirement of severity } \\
\text { than criterion } 1 .\end{array}$ & $\begin{array}{l}\text { Same requirement } \\
\text { of severity than } \\
\text { criterion } 1 \text {. }\end{array}$ & $\begin{array}{l}\text { Same requirement } \\
\text { of severity than } \\
\text { criterion } 1 .\end{array}$ \\
\hline Forecast & $\begin{array}{l}\text { Can present one of the } \\
\text { following degrees: } \\
\text { - Stable, without } \\
\text { perspectives of } \\
\text { improvement } \\
\text { - Can go worse } \\
\text { - It's not possible to } \\
\text { determine }\end{array}$ & $\begin{array}{l}\text { Can present one of the } \\
\text { following degrees: } \\
\text { - } \quad \text { Recoverable with } \\
\text { restrictions } \\
\text { - Stable, without } \\
\text { perspectives of } \\
\text { improvement } \\
\text { - Can go worse } \\
\text { - It's not possible to } \\
\text { determine }\end{array}$ & $\begin{array}{l}\text { Same requirement } \\
\text { of forecast than } \\
\text { criterion } 1 \text {. }\end{array}$ & $\begin{array}{l}\text { Same requirement } \\
\text { of forecast than } \\
\text { criterion } 2 \text {. }\end{array}$ \\
\hline Origin & $\begin{array}{l}\text { All except congenital and } \\
\text { problems in the childbirth }\end{array}$ & $\begin{array}{l}\text { All except congenital and } \\
\text { problems in the childbirth }\end{array}$ & A11 & A11 \\
\hline
\end{tabular}

\begin{tabular}{|c|c|c|}
\hline & 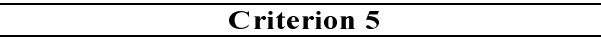 & $\begin{array}{l}\text { Criterion } 6 \\
\end{array}$ \\
\hline Severity & $\begin{array}{l}\text { Can present one of the following degrees: } \\
\text { - } \quad \text { Moderate difficulty } \\
\text { - } \quad \text { Serious difficulty } \\
\text { - } \quad \text { Cannot do the activity }\end{array}$ & Same requirement of severity than criterion 5 . \\
\hline Forecast & $\begin{array}{l}\text { Same requirement of forecast than criterion } 1 \\
\text { and when severity is moderate we consider } \\
\text { that forecast may be: } \\
\text { - Can go wose } \\
\text { - It's not possible to determine }\end{array}$ & $\begin{array}{l}\text { Same requirement of forecast than criterion } 2 \text {, and } \\
\text { when severity is moderate we consider that } \\
\text { forecast may be: } \\
\text { - Can go worse } \\
\text { - It's not possible to determine. }\end{array}$ \\
\hline Origin & $\begin{array}{l}\text { All except congenital and problems in the } \\
\text { childbirth }\end{array}$ & All \\
\hline Objective & \multicolumn{2}{|c|}{ We include degenerative diseases (Parkinson, Alzheimer) } \\
\hline
\end{tabular}

denotes the time passed from one moment to another.

$$
E Y_{W}(t)=w_{t} \Upsilon(t, \tau)+R B \Upsilon(\tau, T)
$$

We follow Lumsdaine et al. (1997) to specify the utility function. Let $U$ denote the utility function and suppose that it includes a systematic predetermined part and a stochastic random one.

The expected utility if continue working $\left(E U_{W}\right)$ can be expressed as follows:

$$
E U_{W}(t)=\sum_{s=t}^{T} \pi(s \mid t) \beta^{s-t}\left[\left(E Y_{W}\right)^{\gamma}+u_{t}\right]
$$

where $\pi(s \mid t)$ denotes the probability of surviving to period $s$ given survival to period $t, \beta$ is the discount factor and $u$ is a random component.

The expected income $\left(E Y_{A}\right)$ in case of applying for disability benefits at time $t$ is given by:

$$
E Y_{A}(t)=\left[a_{t} D B_{t}+\left(1-a_{t}\right) w_{t}\right]
$$

where $a_{t}$ is the probability getting the disability benefits $((D B))$, and $w$ denotes the wage if the application is rejected. Then expected utility of applying for disability benefits $\left(E U_{A}\right)$ is:

$$
E U_{A}(t)=\sum_{s=t}^{T} \pi(s \mid t) \beta^{s-t}\left[\mu^{\gamma} E Y_{A}(t)^{\gamma}+v_{t}\right]
$$


where $\mu$ represents the relative value of income in the post-application state to income in the pre-application state (income may produce more or less utility after application for disability benefits) and $v$ is a random component.

An individual applies for disability benefits if $E U_{A}>E U_{w}$, that is, if:

$$
\sum_{s=t}^{T} \pi(s \mid t) \beta^{s-t}\left[\mu^{\gamma} E Y_{A}(t)^{\gamma}-E Y_{W}(t)^{\gamma}\right]-\sum_{s=t}^{T} \pi(s \mid t) \beta^{s-t} \omega_{t}>0
$$

where, $\omega_{t}=v_{t}-u_{t}$. Finally, the probability of applying for disability benefits at time $t$ :

$$
\operatorname{Pr}[\text { Apply at } t]=\operatorname{Pr}\left[\sum_{s=t}^{T} \pi(s \mid t) \beta^{s-t}\left[\mu^{\gamma} E Y_{A}(t)^{\gamma}-E Y_{W}(t)^{\gamma}\right]>\sum_{s=t}^{T} \pi(s \mid t) \beta^{s-t} \omega_{t}\right]
$$

\subsection{Econometric framework}

Our econometric framework is based on a two-equations latent variable model. ${ }^{7}$ We define two latent unobservable variables corresponding to Social Security's decision of awarding a permanent disability benefit, $r^{*}$, and to the true disability status, $d^{*}$. Those individuals who receive a disability benefit but don't deserve it, consider at the time of the application that they prefer to receive a permanent disability benefit from now on instead of returning to work and waiting until retirement age.

$$
r^{*}=X^{\prime} \beta_{r}+\varepsilon_{r}
$$

where $X$ is a vector of characteristics observed by the Social Security administration, and $\beta_{r}$ is the corresponding vector of parameters. The term $\varepsilon_{r}$ can be interpreted as some kind of information known by the applicant, but unknown by the Social Security. This term can be understood as a "bureaucratic" noise that interferes the assignment process. So $X^{\prime} \beta_{r}+\varepsilon_{r}$ is the score the applicant gets according to Social Security rules using a continuous scale. Applicants with a high score will receive a disability benefit. Instead of $r^{*}$ we observe a binary indicator $r=\mathbf{1}\left(r^{*}>0\right)$.

To represent if the applicant deserves a permanent disability measure we use a similar equation:

$$
d^{*}=Z^{\prime} \beta_{d}+\varepsilon_{d}
$$

where $Z$ is a set of variables that measure health status and $\beta_{d}$ is the corresponding vector of coefficients or "weights". The term $\varepsilon_{d}$ gathers some information that is only known by the applicant. As before, instead of $d^{*}$ we observe the binary indicator $d=\mathbf{1}\left(d^{*}>0\right)$.

We suppose that $\left(\varepsilon_{r}, \varepsilon_{d}\right)$ are distributed as a bivariate normal with zero mean vector, variances normalized to one an correlation coefficient $\rho \in(-1,1)$.

We could, a priori, think that the set of variables $X$ and $Z$ have to be the same. This is true for variables related to disabilities and deficiencies, but there are some variables that can affect the probability of receiving although not the probability of deserving. We specially refer to the place of residence because it does not affect heath status but given that the assignment process depends on Social Security Provincial Departments, some differences in the level of exigency of disability requirements can emerge.

\footnotetext{
${ }^{7}$ See Benítez-Silva et. al, (2005) for an extended version of the model.
} 
As there are only four combinations for the variables $r$ and $d$, the likelihood function can be written in terms of a multinomial distribution:

$$
\begin{gathered}
p_{11}=L\left(r=1, d=1 \mid \beta_{r}, \beta_{d}, \rho, X, Z\right) \\
p_{10}=L\left(r=1, d=0 \mid \beta_{r}, \beta_{d}, \rho, X, Z\right) \\
p_{01}=L\left(r=0, d=1 \mid \beta_{r}, \beta_{d}, \rho, X, Z\right) \\
p_{00}=L\left(r=0, d=0 \mid \beta_{r}, \beta_{d}, \rho, X, Z\right) \\
L\left(r, d \mid \beta_{r}, \beta_{d}, \rho, X, Z\right)=\prod_{\substack{r=1 \\
d=1}} p_{11} \prod_{\substack{r=1 \\
d=0}} p_{10} \prod_{\substack{r=0 \\
d=1}} p_{01} \prod_{\substack{r=0 \\
d=0}} p_{00}
\end{gathered}
$$

This likelihood function can also be expressed as:

$$
\begin{aligned}
L\left(r, d \mid \beta_{r}, \beta_{d}, \rho, X, Z\right)= & \prod_{\substack{r=1 \\
d=1}} \Phi_{2}\left(X \beta_{r}, Z \beta_{d}, \rho\right) \prod_{\substack{r=1 \\
d=0}} \Phi_{2}\left(X \beta_{r},-Z \beta_{d},-\rho\right) \\
& \prod_{\substack{r=0 \\
d=1}} \Phi_{2}\left(-X \beta_{r}, Z \beta_{d},-\rho\right) \prod_{\substack{r=0 \\
d=0}} \Phi_{2}\left(-X \beta_{r},-Z \beta_{d}, \rho\right)
\end{aligned}
$$

where $\Phi_{2}$ denotes the bivariate normal distribution function.

\subsection{Description of the data}

As stated, our main data source is the Disabilities, Deficiencies and Health Status Survey (DDHSS) carried out by the Spanish National Bureau of Statistics in 1999. A sample of 70,402 households and 218,185 people were interviewed, from which 10,484 were less than 6 years old and 207,701 were 6 or more years. [see the Appendix A for further details on survey characteristics and Appendix B for a description of disabilities and the variables employed in the empirical analysis.] We apply several filters to the original file in order to get the relevant samples (see Table 2 for a summary) for the purposes of our study:

1. Initial sample (sample A): We select individuals in the 45-59 age range, for which disability is likely to constitute a pathway to a permanent exit from the labor force. However, we keep observations for younger individuals to draw comparisons with older individuals and make more evident the various policies in place.

A The surviving sample has 19442 males and 20489 females.

2. Restricted initial sample (sample B): we apply the following restrictions to sample A:

(a) We eliminate individuals without a contributive career.

(b) We eliminate the individuals that are working but whose professional situation is unknown.

B This leaves a sample of 18235 males and 8142 females. In these samples there are individuals with and without disabilities and we are going to use them for exogeneity and consistency tests. ${ }^{8}$

\footnotetext{
${ }^{8}$ Those individuals who do not suffer any disability do not answer to the Disabilities and Deficiencies Questionnaire. We do not know if they have an impairment certificate, need a caretaker, have finished a rehabilitation treatment or have changed of house because of a disability. But we suppose that the answer to all these questions is negative because otherwise they would have filled in the questionnaire.
} 
Table 2: Description of the samples

\begin{tabular}{|l|l|l|l|}
\hline Sample & Characteristics & Gender:Size & Purposes \\
\hline A & Individuals aged 45-59 & $\begin{array}{l}\text { Men: 19442 } \\
\text { Women: 20489 }\end{array}$ & Screening mechanism \\
\hline B & $\begin{array}{l}\text { + some requirements on } \\
\text { economic activity }\end{array}$ & $\begin{array}{l}\text { Men: 18235 } \\
\text { Women: } 8142\end{array}$ & $\begin{array}{l}\text { Exogeneity and consistency test } \\
\text { Bivariate probit }\end{array}$ \\
\hline B1 & $\begin{array}{l}\text { Ind. with disabilities } \\
+ \text { requirements on LFS }\end{array}$ & $\begin{array}{l}\text { Men: } 984 \\
\text { Women: 552 }\end{array}$ & $\begin{array}{l}\text { Rational expectations test } \\
\text { Bivariate probit }\end{array}$ \\
\hline B0 & $\begin{array}{l}\text { Ind. w/ disabilities } \\
+ \text { requirements on LFS }\end{array}$ & $\begin{array}{l}\text { Men: 16980 } \\
\text { Women: 7461 }\end{array}$ & $\begin{array}{l}\text { Prob of receiving } \\
\text { being healthy }\end{array}$ \\
\hline
\end{tabular}

3. Sample with disabilities (sample B1). This sample is constructed by applying the following criteria to sample B:

(a) We drop all individuals that do not answer the Disabilities Questionnaire.

(b) From the sample of individuals who receive a permanent disability benefit and answer the Disabilities Questionnaire we eliminate 145 observations for which we do not know the occupation and 255 observations for which we do not know the labor force status before receiving the benefit.

In this sample, we define a binary variable that takes the value one if the individual is receiving a contributive permanent disability benefit. However this situation is not incompatible with an active labor force status. For example, $6.43 \%$ of men and $2.02 \%$ of women are also working and $2.66 \%$ of men and $0.81 \%$ of women are looking for a job.

B1 That leaves a sample of 984 men and 552 women. We perform the rational expectations test with this final sample.

4. Sample without disabilities (sample B0).

B0 Those observations in sample B that are not assigned to sample B1, excluding the ones that have been eliminated, are assigned to sample B0. The resulting sample consist of 16980 males and 7491 females.

\subsection{A first look at the data}

First of all, from the sample of 984 men and 552 women, $20.05 \%$ of men and $13.99 \%$ of women who receive a benefit do not deserve it using our preferred criterion \#6. So, the award error is much larger for men than for women ${ }^{9}$. There are several disabilities that are not present among individuals who receive but do not deserve the benefit (disability for global visual tasks, for hearing any sound, for communicating through alternative languages, not sealed gestures or reading-writing, for remembering people/objects or informations/past episodes and for executing simple or complex orders are examples). Among women in the award error area there is nobody with disabilities for hearing strong sounds, listening the speech, maintaining body postures, washing oneself, controlling physical needs, eating and drinking, dressing and undressing. On the other hand, individuals who receive but do not deserve usually declare to suffer osteoarticular or

\footnotetext{
${ }^{9}$ See Appendix C, tables C.2 and C.3 for descriptive statistics.
} 
musculoskeletal deficiencies in column and upper and low extremities, and disabilities for moving not heavy objects and using utensils and tools. Undoubtedly, these deficiencies are painful, but is difficult to check how severe they are (Pérez Rueda et al., 2000). Moreover, none of these individuals needs a caretaker for daily activities. As regards those individuals who receive and deserve, the most common disabilities are for getting up and down, moving not heavy objects, moving without way of transport, going in public transport or driving own vehicle.

A look at socioeconomic characteristics (Table C.4) reveals that there are more married men pensioners than women, and $90 \%$ of men who do not deserve are household breadwinners. Approximately half of pensioners that deserve are between 55 and 59 years old and around $30 \%$ of those who do not deserve belong to this age interval. A majority of male pensioners only have elementary education that previously were skilled workers. Also a majority of female pensioners only have elementary education but were mainly unskilled workers.

In Table C.5 we report the spouse's labor force status for married/cohabiting individuals in sample. If he/she is married but is not a pensioner, the probability of observing the spouse working is higher than if he/she is a pensioner and deserves, and twice larger than if he/she is pensioner and does not deserve. In all cases, the probability of husband working is twice the probability of wife working. It is very interesting to realize that if he/she is a pensioner and does not deserve the probability that the spouse receives a permanent disability benefit is five times than if he/she is not a pensioner. This result is more evident for the case of husbands $(37.5 \%$ with respect to $9.06 \%$ ). Finally, when the husband is a pensioner there is a higher percentage of houseworker wives. Alternatively, when the wife is the pensioner the husband is more likely to be in any other situation.

\section{Diagnostics on the disability indicators}

With the intention of determining which one of the six disability indicators previously defined best represents the legal benchmark of permanent disability given by the Social Security we perform three diagnosis tests. The surviving indicator will be used in the estimation of the permanent disability benefit award rate.

\subsection{Exogeneity test}

As already mentioned before, the exogeneity of self-reported disability status is quite controversial. Before estimating the model and using the results with policy purposes, we would like to be sure that the deserving indicator is strictly exogenous. Possible endogeneity of the regressor coupled with measurement errors would lead to inconsistent estimations (Benítez-Silva et al., 2004, 2005). We use Heckman's (1978) proposal using a two equation system to make such a test. The first structural equation represents the Social Security award decision and the second one indicates whether the individual deserves a disability benefit:

$$
\begin{aligned}
r_{i}^{*} & =X_{1 i} \beta_{1}+d_{i} \alpha_{1}+u_{1 i} \\
d_{i}^{*} & =X_{2 i} \beta_{2}+u_{2 i}
\end{aligned}
$$

where $r^{*}$ and $d^{*}$ are two latent continuous variables, $X_{j}, j=1,2$ are vectors of exogenous variables referred to disabilities and deficiencies, and $\left(u_{1}, u_{2}\right)$ are jointly normal with zero mean vector, variances normalized to one and correlation coefficient $\rho \in(-1,1)$. To achieve identification we follow a two step procedure: we, first, regress the deserving and receiving indicator over the set of disabilities and deficiencies; in a second step we drop the variables with non-significant coefficients. After imposing these exclusion restrictions, we estimate a bivariate probit using the 
Table 3: Exogeneity test on the restricted initial sample (sample B).

\begin{tabular}{|l|r|r|r|r|}
\cline { 2 - 5 } \multicolumn{1}{c|}{} & \multicolumn{2}{c|}{ Men $[\mathrm{N}=18.235]$} & \multicolumn{2}{c|}{ Women $[\mathrm{N}=8.142]$} \\
\cline { 2 - 5 } \multicolumn{1}{c|}{} & Statistic & $\mathrm{p}$-value & Statistic & $\mathrm{p}$-value \\
\hline Criterion 1 & 6.6919 & 0.0071 & 2.5732 & 0.2698 \\
Criterion 2 & 5.2417 & 0.0299 & 1.6519 & 0.4846 \\
Criterion 3 & 2.4496 & 0.2936 & 1.2539 & 0.6020 \\
Criterion 4 & 1.1703 & 0.6282 & 0.6004 & 0.8136 \\
Criterion 5 & 0.9991 & 0.6829 & 0.0085 & 0.9976 \\
Criterion 6 & 0.0172 & 0.9951 & 0.0032 & 0.9990 \\
\hline
\end{tabular}

restricted initial sample (sample B). In this context the exogeneity of the deserving equation can be checked by means of the test $\rho=0$.

Another possibility to test exogeneity of the deserving indicator is the Lagrange multiplier test. Under the null of exogeneity, the model is composed by two independent probit equations and bivariate probabilities and densities coincide with the product of the corresponding marginal ones. To construct the test we follow Kiefer (1982) and Greene (1993). ${ }^{10}$ First, we define $\delta_{1 i}=\gamma_{1 i} \beta_{1}^{\prime} X_{1 i}$ and $\delta_{2 i}=\gamma_{2 i} \beta_{2}^{\prime} X_{2 i}$ where $\gamma_{i 1}=2 r_{i}-1$ and $\gamma_{i 2}=2 d_{i}-1, r$ and $d$ are the binary indicators of the events $\mathbf{1}\left(r^{*}>0\right)$ and $\mathbf{1}\left(d^{*}>0\right)$, respectively. Given this notation the joint log-likelihood can be written as

$$
L^{*}=\ln L=\sum_{i=1}^{n} \ln \Phi_{2}\left(\delta_{1 i}, \delta_{2 i}, \rho^{*}\right)
$$

where $\rho^{*}=\gamma_{i 1} \gamma_{i 2} \rho$. The LM or score test is a quadratic form which uses the first derivatives of the unrestricted likelihood function whose weighting matrix is the inverse of the information matrix for the unrestricted likelihood function when both equations are evaluated under the null. The statistic is distributed according to a $\chi^{2}$ with one degree of freedom.

$$
L M=\left(\frac{\partial L^{*}}{\partial \theta^{\prime}}\right)^{\prime}\left(\frac{\partial^{2} L^{*}}{\partial \theta \partial \theta^{\prime}}\right)\left(\frac{\partial L^{*}}{\partial \theta^{\prime}}\right) ; \theta=(\beta, \rho)
$$

Substituting we get:

$$
\begin{aligned}
L M & =\frac{f^{2}}{h} \\
\text { where } f & =\sum_{i} \gamma_{1 i} \gamma_{2 i} \frac{\phi\left(\delta_{1 i}\right)}{\Phi\left(\delta_{1 i}\right)} \frac{\phi\left(\delta_{2 i}\right)}{\Phi\left(\delta_{2 i}\right)} \quad \text { and } h=\sum_{i} \frac{\left[\phi\left(\delta_{1 i}\right) \phi\left(\delta_{2 i}\right)\right]^{2}}{\Phi\left(\delta_{1 i}\right) \Phi\left(-\delta_{1 i}\right) \Phi\left(\delta_{2 i}\right) \Phi\left(-\delta_{2 i}\right)}
\end{aligned}
$$

Table 3 reports the exogeneity test by gender for the set of criteria defined. We cannot reject the null of exogeneity for indicators 3 to 6 in the case of men and for any criterion in the case of women, at standard significance levels. This implies that, for the case of men, the indicators that consider disabilities with highest levels of severity and excludes congenital and childbirth problems as possible origin of the deficiency, are rejected. Consequently, a preferred disability criteria should be capable of gathering degenerative pathologies whatever origin they could have.

\footnotetext{
${ }^{10}$ See Rivers and Vuong (1988) for an exogeneity test in probit models. Recently, Fabbri et al (2005) discussed the statistical properties of LM test and other alternatives in simultaneous discrete choice models.
} 
Table 4: Consistency test. Restricted initial sample (sample B).

\begin{tabular}{|c|c|c|c|c|c|c|c|c|c|}
\cline { 3 - 9 } \multicolumn{2}{c|}{} & \multicolumn{8}{c|}{ Men $(\mathrm{N}=18235)$} \\
\cline { 3 - 10 } \multicolumn{2}{c|}{} & \multicolumn{2}{c|}{ Criterion 3} & Criterion 4 & Criterion 5 & \multicolumn{2}{c|}{ Criterion 6} \\
\cline { 3 - 10 } \multicolumn{2}{c|}{} & Stat & p-val & Stat & p-val & Stat & p-val & Stat & p-val \\
\hline OLS & $F_{(63,18171)}$ & 1.76 & 0.0002 & 1.76 & 0.0002 & 1.36 & 0.0313 & 1.01 & 0.4525 \\
Probit & $\chi_{63}^{2}$ & 86.81 & 0.0251 & 89.20 & 0.0166 & 96.66 & 0.0041 & 73.40 & 0.1740 \\
M Logit & $\chi_{63}^{2}$ & 93.20 & 0.0080 & 95.55 & 0.0051 & 104.47 & 0.0008 & 81.44 & 0.0590 \\
\hline & & \multicolumn{8}{|c|}{ Women $(\mathrm{N}=8142)$} \\
\hline OLS & $F_{(63,8078)}$ & 1.47 & 0.0097 & 1.57 & 0.0028 & 1.27 & 0.0736 & 1.15 & 0.1920 \\
Probit & $\chi_{63}^{2}$ & 93.55 & 0.0075 & 92.06 & 0.0099 & 51.22 & 0.8560 & 52.97 & 0.8122 \\
M Logit & $\chi_{63}^{2}$ & 99.72 & 0.0022 & 98.55 & 0.0028 & 52.97 & 0.8122 & 63.12 & 0.4720 \\
\hline
\end{tabular}

\subsection{Consistency test}

The second diagnosis refers to consistency. We want to verify if what individuals believe to be disabled is, coincides, in expected terms, with Social Security actual definition of permanent disability. Therefore, we test whether the deserving indicator based on self-reported disability status is an unbiased estimator of the permanent disability award indicator. We test that:

$$
E[r-d \mid X]=0
$$

where $X$ is the same vector of 36 disabilities and 27 deficiencies used for the exogeneity test. Unbiasedness can be tested through different ways. First, we can regress, by LS, $(r-d)$ on a set of explanatory variables and test the hypothesis that all coefficients are equal to zero. Second, using a multinomial logit model we can regress $(r-d)$ over the same set of explanatory variables and test the same hypothesis using a likelihood ratio test against a restricted model which only includes a constant. Finally, we can perform a likelihood ratio test using the results of a probit model of $|r-d|$ on a set of variables against a restricted probit model which only includes a constant term. In all three cases we use the restricted initial sample or sample B.

The results of the test are reported in Table 4. We have only carried consistency test for criteria 3 to 6 because of criteria 1 and 2 did not satisfy exogeneity and we are looking for a valid disability indicator for both men and women. For men, only criterion 6 satisfies all consistency tests, and for women both criteria 5 and 6 are valid under the results of these diagnostics. Therefore, in what follows we use criterion 6 both for men and women. This implies that the only surviving disability indicator is the one that considers all possible origins of the deficiency and includes moderate disability associated with an unfavorable prognosis.

This criteria includes congenital and childbirth problems because accepting that the pathology has to be a sudden coming as general principle, it is necessary to distinguish to disease from the disability, since the decisive element is not that the first one was present in affiliation date but the moment in which the disability appears. It also contains moderate severe disability that can go worse in the future. The justification is that what defines permanent disability is not the lack of health but the binomial disease - profession or the relation between sequels and reduction of the abilities for the work. Nevertheless, the exigency of permanency has to be reeled to reasonable terms, since, the law admits the future possibility of recovery, through the figure of the improvement review, institution that eliminates the risk of a life declaration without possibility of repeal. 
Table 5: Rational expectations test. Restricted initial sample (sample B1).

\begin{tabular}{|l|r|l|}
\cline { 2 - 3 } \multicolumn{1}{c|}{} & Test $\hat{\beta}_{r}=\hat{\beta}_{d}$ & $\mathrm{p}$-val \\
\hline Men $(\mathrm{N}=984)$ & $\chi_{48}^{2}=48.10$ & 0.4689 \\
Women $(\mathrm{N}=552)$ & $\chi_{48}^{2}=54.98$ & 0.1981 \\
\hline
\end{tabular}

\subsection{Unbiased individuals' disability evaluation test}

The results of the previous sections suggest that the deserving indicator based of self-reported disability status is an exogenous determinant and consistent estimator of the Social Security award decision. However, the tests presented above are based on asymptotic properties of the relevant test statistics, but in small samples they might have little power. Our key hypothesis is that applicants have a through understanding of the award process, including full knowledge of the weights $\beta_{r}$ that Social Security places on various characteristics $X$, so the null hypothesis that we want to test is:

$$
\beta_{r}=\beta_{d}
$$

If the rational expectations hypothesis holds, then the deserving indicator constitutes a valid measure of the degree of disability required for receiving a disability benefit, and it can be used to measure the magnitude of the classification errors in the permanent disability benefits award process $^{11}$.

Table 5 provide the results for the sample of men and women that have declared to suffer some disability (sample B1). We have estimated a bivariate probit model in which we have included as explanatory variables the same disabilities and deficiencies for the Social Security and for the applicant's equation. For both samples we cannot reject, at standard significance levels, the null hypothesis that the parameter vectors are equal.

In Figure 1 we plot the estimated density functions for both the awarding and deserving decisions by gender. Note that that deserving' density function is slightly more skewed to the right than the corresponding to Social Security. This means that is more difficult for the Social Security to distinguish between individuals with the same observable variables than it is for the individuals themselves. For women this result is even more evident. This is an implication of the rational expectations test, because it shows that individuals have internalized the rules that Social Security uses in the process of awarding benefits.

\section{$5 \quad$ Empirical results}

In this section we present the results of the empirical analysis by gender for two different subsamples: (a) individuals with disabilities (sample B1); and, (b) individuals without disabilities (sample B0).

\subsection{Individuals with disabilities}

We have estimated a common probit model for the decisions of deserving and receiving a permanent disability benefit (see Table D.1) restricting the sample to individuals with disabilities (sample B1). We assume that deserving precedes in time to receiving. Having a disability or deficiency has a positive and significant impact on both equations. We find some additional variables with significative impact on the probabilities: age between 55 and 59, change of house because

\footnotetext{
${ }^{11}$ See Benítez-Siva et al., 2004 and 2005 for further analysis on unbiased reporting.
} 
Figure 1: Estimated density functions by model and gender

\section{Social Security (Men)}

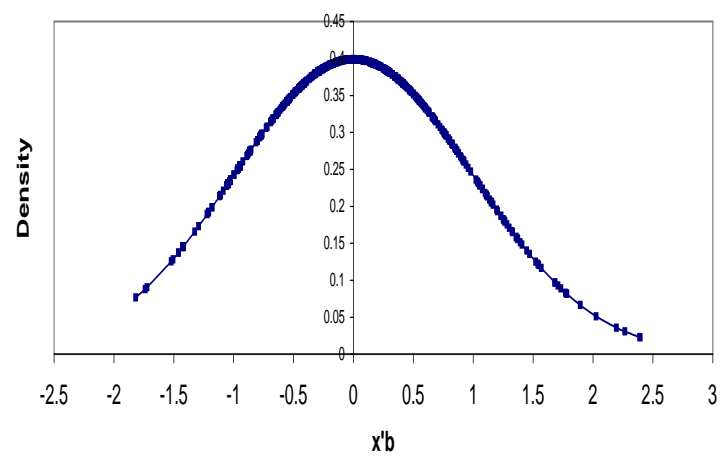

Deserving indicator (Men)

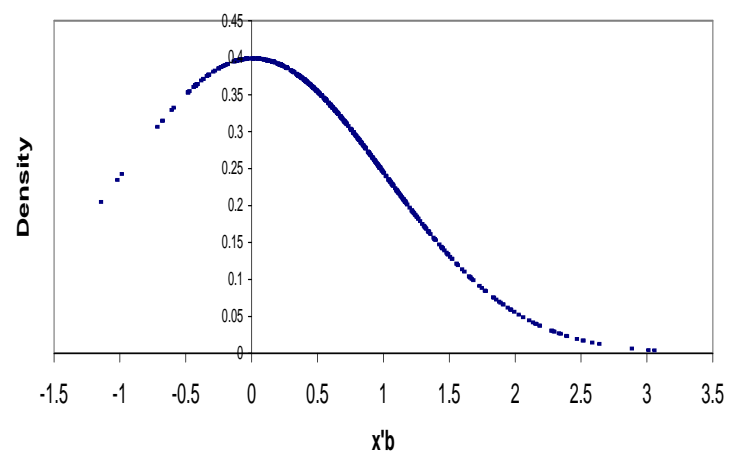

Social Security (Women)

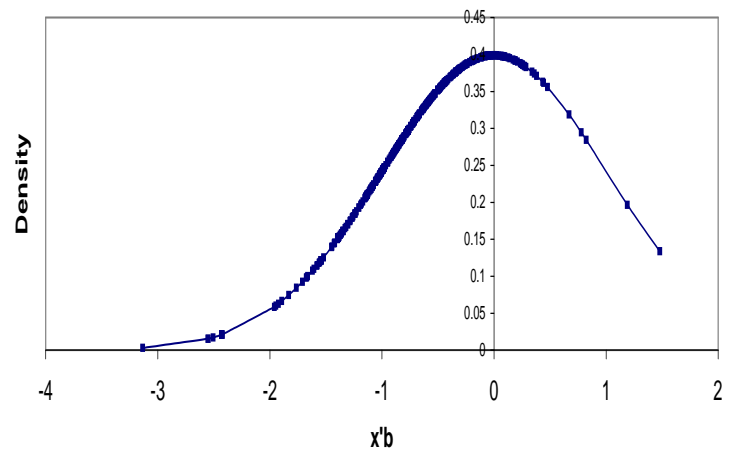

Deserving indicator (Women)

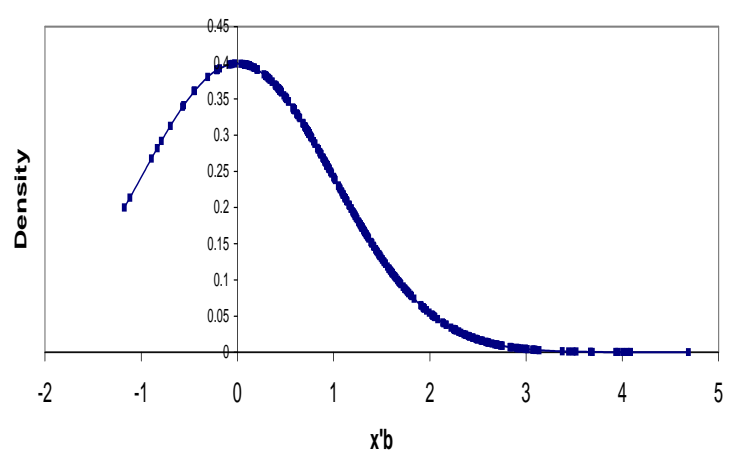

of a disability, impairment certificate, caretaker, rehabilitation treatment, level of education, active, unemployed and professional occupation. However, the married and main breadwinner dummies, the variables related to the economic activity of the spouse, and the place of residence are not significant in the deserving equation. These results should not cause any surprise since these variables are supposed not to affect the health status. But interestingly, all these determinants have significant effects in the receiving equation, for both men and women. Also very important is the effect of regional dummies. All of them are significant in the receiving equations and non-significant in the deserving ones (for both gender). Living in Murcia (the omitted region) seems to guarantee the highest probability of receiving a disability benefit. Andalucia and Extremadura, for men, and only Andalucia, for women, are also significant although their coefficients are slightly smaller than those from Murcia.

In order to evaluate the marginal effects we use the following baseline: men/women less than 55 years old, not married, college education, white collar occupation, living in Murcia, with only disabilities of moderate severity, without impairment certificate, that has not received treatment of rehabilitation nor changed of residence because of a disability and that does not need caretaker ${ }^{12}$. The baseline probabilities of deserving are 0.324 for men and 0.211 for women.

\footnotetext{
${ }^{12}$ Marginal effects for men are reported in Table D.2, and table of marginal effects for women are available on request.
} 
Figure 2: Difference between the Social Security decision and the deserving indicator by gender
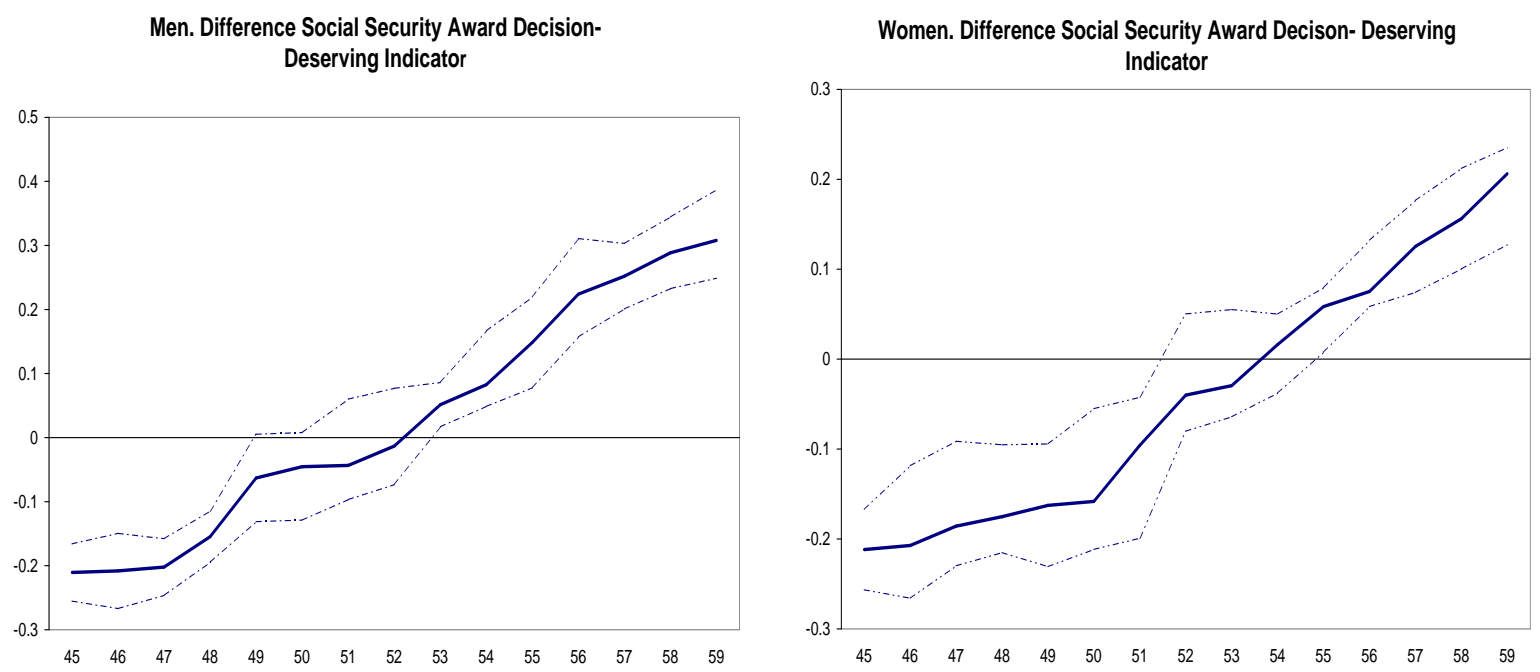

We could think that these probabilities are too high given that individual only suffers disabilities of moderate severity. But we have to take into account that although we have tried to consider the maximum number of daily living activities when elaborating the self-reported disability indicators, there are several unobserved factors such as pain or personality that cannot be controlled for (Pérez Rueda et al., 2000). The baseline probabilities of receiving are 0.439 for men and 0.295 for women. That is, they are $40.31 \%$ and $40.29 \%$ higher than the corresponding deserving probabilities. Moreover, men have a probability of deserving and receiving higher than women (53.68\% and $47.61 \%$, respectively), but differences between deserving and receiving are about the same regardless the gender.

[REVISE] We have performed a linear regression of the difference between the Social Security awarding decision and the deserving indicator for both samples. Afterwards, we have plotted the predicted probability of the difference for each age and the confidence interval at $95 \%$ of significance (see Figure 2). The most significant result is that we observe a positive predicted value, that is, benefit awarded by Social Security but undeserved according to the disability indicator, mostly for individuals older than 55. This is a confirmation that awarding error is positively correlated with age, and that undue benefits are mainly awarded to workers near to early retirement age.

Disabilities, deficiencies and health variables Table 6 shows for both genders the disabilities whose marginal effects are the highest, both for deserving and receiving. The only disabilities with similar deserving and receiving probabilities are going in public transport for men and communicating for women. For men, the probability of deserving is smaller than the probability of receiving for deficiencies in upper an lower extremities (152.61\%), houseworking (96.89\%) and communicating (53.21\%). As regards women, the same happens for executing orders $(165.81 \%)$, moving inside home $(61.09 \%)$ and maintaining body postures $(60.02 \%)$. Disabilities for moving inside home, houseworking and maintaining body postures are related to deficiencies in the vertebral column and upper and lower extremities. In most cases they have an osteoarticular origin (arthritis, rheumatism, curvature of the spine, disc hernia) and this make diagnosis quite difficult because the aptitude for bearing pain is neither measurable not 
Table 6: Key marginal effect of disabilities in both the probability of deserving and receiving.

\begin{tabular}{|l|l|l|}
\cline { 2 - 3 } \multicolumn{1}{c|}{} & \multicolumn{1}{c|}{ Deserve } & \multicolumn{1}{c|}{ Receive } \\
\hline \multirow{3}{*}{ Men } & Relating to people $(98.26 \%)$ & Relating to people $(47.79 \%)$ \\
& Looking after oneself $(64.11 \%)$ & Houseworking $(46.71 \%)$ \\
& Moving inside home $(56.6 \%)$ & Communicating (40.52\%) \\
& Going in public transport $(48.78 \%)$ & Going in pub. trans. $(33.86 \%)$ \\
\hline \multirow{5}{*}{ Women } & Seeing (156.57\%) & Executing orders (144.02\%) \\
& Communicating $(128.95 \%)$ & Communicating (106.46\%) \\
& Vertebral column $(121.21 \%)$ & Hearing (81.71\%) \\
& Going in pub. trans. $(111.44 \%)$. & Houseworking (54.79\%) \\
\hline
\end{tabular}

unobservable.

Age is another important determinant of both probabilities. The probability of deserving increases 8.28 and 30.64 for men and women, respectively. Interestingly, the probability of receiving is higher than the probability of deserving ( $45.02 \%$ for men and $24.69 \%$ for women). Without any doubt, these results illustrate that disability pensions have been used to ease transitions to retirement before the age benefits are first available (an issue mentioned by Boldrin et al., 1999).

Needing a caretaker for daily living activities increases the deserving probability in $92.46 \%$ for men and $40.73 \%$ for women. This variable is quite trustworthy because an individual who needs somebody to take care of him deserves and should receive a disability benefit. Whether an individual has changed of house because of a disability, produces an increase in the receiving probability of $53.03 \%$ for men and $66.73 \%$ for women. If he/she has an impairment certificate, raises these probabilities by $59.84 \%$ for men and $77.17 \%$ for women. It is important to underline that for the case of men with an impairment certificate, the probability of receiving nearly doubles the deserving one. This implies that the impairment certificate, which gives some fiscal advantages, is being used for purposes other than getting disability benefits.

Finally, for women, having completed a treatment of rehabilitation increases the deserving and receiving probabilities by $8.16 \%$, and $4.33 \%$, respectively. The impact is significatively greater for men with corresponding figures of $14.68 \%$ and $25.57 \%$.

Socioeconomic variables Being unemployed increases the probability of deserving by $52.49 \%$ for men and $31.88 \%$ for women ${ }^{13}$. This may be because poor health workers have a higher probability of becoming unemployed and experiment longer periods of unemployment than others (Stewart, 2001; Ruhm, 2000, 2003), but also because the unemployed face lower opportunity costs of applying for disability benefits than employed, that is, they would not apply for benefits while employed but will do it in the event of job loss (Autor and Duggan, 2003). However, the receiving probability when unemployed decreases by $25.18 \%$ for men and $94.78 \%$ for women. Perhaps, there exist certain reticences for awarding disability benefits to unemployed workers to avoid the phenomenon known as "hidden unemployment" (Parsons, 1980 ; Haveman and Wolfe, 1984a).

An endogeneity problem for the variable unemployed would imply that poor health is the cause rather than the consequence of losing ones job. To check what is the main reason of unemployment we have used one of the questions of the DDHS survey: "Have you changed your

\footnotetext{
${ }^{13}$ The binary variable "unemployed" takes the value one in two cases: first, if at the time of the survey the individual is unemployed; and second, if the individual is receiving a permanent disability benefit but his labor force status before becoming pensioner was unemployed.
} 
relation with economic activity due to a disability?". From the sample of 984 men (552 women), there are 85 men ( 70 women) unemployed, from which only 11 men ( 9 women) answered in the affirmative to the previous question, indicating also that they were working before health shock and just afterwards became unemployed. We consider that this percentage $(12.94 \%$ for men, $12.85 \%$ for women) is very reduced and we can avoid any endogeneity problem.

Clearly marital status and household breadwinner are additional policy variables for benefit concession. While marital status is not significant in the deserving equation, being married increases the receiving probability by $8.65 \%$ for men and $1.66 \%$ for women. Moreover, if the individual is the head of the household, the receiving probabilities increase $7.53 \%$ for men and $18.86 \%$ for women.

Concerning variables related to the economic activity of the spouse ${ }^{14}$, if the individual is a pensioner the probability that the spouse is working decreases $10.65 \%$ for men and $28.87 \%$ for women. On the other hand, there is a positive correlation for the case of both spouses being disability pensioners. If one spouse receives a disability benefit, the probability that the other also receives benefits increases by $22.47 \%$ for men and $35.46 \%$ for women. This evidences some scale economies in benefit claim (when one of the spouses is a pensioner, he/she knows the awarding mechanism and it is easier for the other spouse to apply for it) and/or complementarities in leisure.

The probability of deserving increases $93.01 \%$ for men ( $61.23 \%$ for women) when moving from college education and white collar occupation to elementary education and unskilled job. It also increases $49.55 \%$ for men $(39.43 \%$ for women) when moving to high school level and skilled job. The deserving probability increases more when moving from college-white collar to high school-white collar (49.36\%) than when moving to college-skilled (12.95\%), for men. For women, we can observe that the opposite is true, although differences are smaller $(17.10 \%$ in the first case and $21.37 \%$ in the second one).

The receiving probability achieves its maximum when the individual has elementary education and an unskilled job, and it decreases as the level of education and/or the quality of occupation increases. In this sense, Autor and Duggan (2003) account for the role of disability benefits in inducing labor force exit among the low-skilled workers. For both gender, the probability of receiving increases more with the educational level than with the occupation. Moreover, it seems to have a relationship with the manual character of the jobs. ${ }^{15}$ Table 7 , which crosstabulates the prevalence of hands and fingers disabilities with skill by gender, strongly supports this argument, since these disabilities are very concentrated in unskilled (female) workers.

Undoubtedly the region of residence hides additional policy tools for benefit concession: the level of income and the fraction of agricultural workers: individuals in the low-income and highfraction of agricultural workers regions of Murcia, Andalucia and Extremadura, have significantly higher probabilities of receiving benefits than individuals in other regions (see Table C.1). We will develop further this argument in the next section.

\subsection{Individuals without disabilities}

We have conducted a final test of the awarding process in the subsample which only contains individuals without disabilities (16980 men and 7461 women, sample B0). Our purpose is to study the probability of receiving a benefit conditional on being healthy (Table D.3), that is

\footnotetext{
${ }^{14}$ Several studies, for example Peracchi and Welch (1994), Blau and Riphahn (1999) or Jiménez et al. (1999) have observed that the spouse's labor force status affects retirement behavior of the other member of the couple. In this paper we have proxied the spouse's labor status using two dummy variables indicating whether he/she is working or receiving a permanent disability benefit.

${ }^{15}$ For example: assembly lines, seamstresses in court and confection workshops, workmen of toys factories, replacers of supermarkets. In all these occupations, there are many unskilled workers that become unable for doing their jobs if they suffer any kind of manual disability.
} 
Table 7: Manual disabilities and skill level

\begin{tabular}{|l|r|r|r|r|r|r|}
\cline { 2 - 7 } \multicolumn{1}{c|}{} & \multicolumn{3}{c|}{ Men (N=984) } & \multicolumn{3}{c|}{ Women (N=552) } \\
\cline { 2 - 7 } \multicolumn{1}{c|}{} & White collar & Skilled & Unskilled & White collar & Skilled & Unskilled \\
\hline Moving not heavy objects & 16.32 & 34.21 & 49.47 & 14.81 & 17.28 & 67.90 \\
Using tools & 11.39 & 33.66 & 54.95 & 13.51 & 14.86 & 71.62 \\
Manipulating small objects & 14.60 & 32.12 & 53.28 & 15.32 & 12.61 & 72.07 \\
\hline
\end{tabular}

the probability of receiving a benefits solely on economic grounds. We specify the conditional probability model as a Probit. The set of explanatory variables includes controls for education, place of residence, marital status, main household breadwinner and age group. We are not able to capture differences related to the activity sector or professional situation since they are not available for non-working pensioners. Once we have estimated the model, we compute the marginal effects with respect to a baseline individual with the following characteristics: single, no breadwinner, high school education and living in Asturias or Cantabria. The results are reported in Table D.4.

The probability of receiving a benefit being healthy sharply increases with the age group (the probability of receiving a benefit for those aged 55-59 practically doubles that of those aged 45-49), and decreases with education and for those that are main breadwinner for both gender. Partially in contrast with the results for individuals with disabilities, by region the probability of receiving a benefit conditional on being healthy is much higher in Asturias-Cantabria (specially for men), Murcia (specially for women) Andalusia and, to a lesser extend, in Extremadura than in any other region. This confirms that policymakers allow some healthy individuals to get (disability) benefits without any penalties and, more importantly, without any disability, before the early retirement age, specially in poorer (see Table C.1) Northern regions (such as AsturiasCantabria) and Southern regions such as Andalucia and Extremadura. Thus, as in many other EU countries disability benefits, disability benefits have been used with redistributive purposes, in order to increase per capita income is some depressed regions.

\section{An alternative mechanism for awarding disability benefits}

In this section we propose a simple screening alternative to the Social Security awarding process ${ }^{16}$. We evaluate the relative efficiency, evaluated by the award error, committed by both methods of classification. The best mechanism will be that providing the minimum number of undeserved disability benefits.

If the Social Security were to know the true disability status of the applicants, $d^{*}$, would use this information in the process of awarding benefits. We have mentioned that some individuals have incentives to misreport to Social Security, but these incentives disappear when they are answering a private and confidential survey. Under the hypothesis of rational expectations, we can regress our preferred deserving indicator (based on self-reported measures) on a set of explanatory variables $X .{ }^{17}$ After estimation, we compute the probability of deserving conditional

\footnotetext{
${ }^{16}$ See Benítez Silva et al. (2005) for an alternative screening mechanism.

${ }^{17}$ In the probit model the dependent variable is the preferred criterion \# 6 . The set of explanatory variables includes: rehabilitation treatment, caretaker, impairment certificate, change of house because of a disability and the 36 disabilities mentioned in Appendix C.1. With respect to disabilities we have defined a dummy variable that takes the value one if disability is suffered with moderate or higher severity and with a prognosis different from recoverable. The size of the sample is bigger than in the bivariate probit model because we do not need to drop observations for which some economic variables are unknown. That's why we can estimate all disabilities separately. The results of the estimation procedure are available on request.
} 
Figure 3: Estimated probabilities of deserving a benefit. Probit estimates

Men

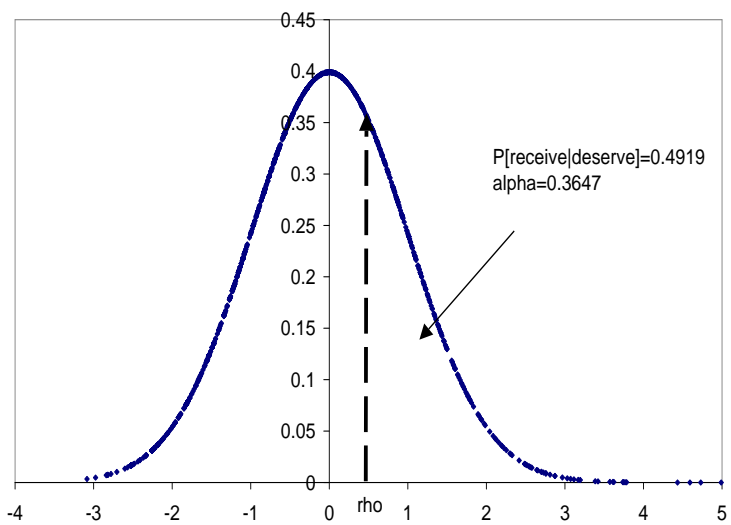

Women

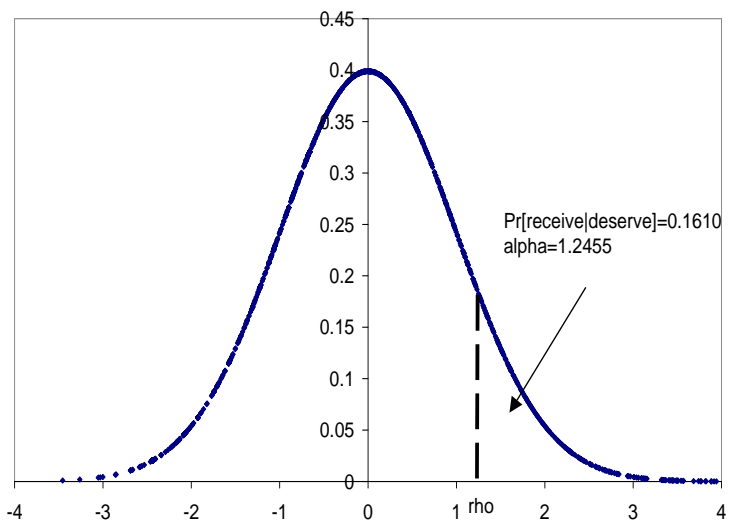

on $X, \hat{P}(d \mid X)$. Then, we award $(A)$ a benefit to those individuals having a probability of deserving above a given threshold, $\alpha \in[0,1]$ :

$$
A=I\{\hat{P}(d \mid X) \geq \alpha\}
$$

Adjusting the level of $\alpha$ we obtain different percentages of benefits, the bigger $\alpha$ the smaller the number of disability benefits.

Consider that the Social Security administration objective is to achieve a given fraction of disability pensions, say $p$. Then $\alpha$ would be given by the minimum of the following expression:

$$
\underset{\alpha}{\operatorname{Min}} p=\int I\{\hat{P}(d \mid X) \geq \alpha\} f(X) d X
$$

We can compute the sample analog of expression (2) and obtain the optimal value of $\alpha$, say $\hat{\alpha}$, for which the percentage of individuals which receive benefits is equal to the Social security objective, $p$.

Figure 3 shows the corresponding density function for both men and women. We indicate with a discontinuous line the index $(\alpha)$ that makes the right tail equal to the probability of receiving a disability benefit conditioned to deserving it ${ }^{18}$. This probability is 0.4919 for men and 0.1610 for women, and the corresponding indexes are 0.3647 for men and 1.2455 for women, with a standard deviation equal to 0.0016 and 1.2455 , respectively.

We award a disability benefit to those individuals with a value of $\hat{P}(d \mid X)$ greater than $\hat{\alpha}$. Then we compare the efficiency between the Social Security and the screening mechanism. Our mechanism will be better than Social Security if satisfies three requirements. First, reduces the number of individuals that receive with Social Security but don't deserve. Second, includes all individuals that are receiving according to Social Security and deserve. And third, doesn't award benefits to new individuals who don't deserve it.

\subsection{Results}

Table 8 presents some summary measures obtained from the analysis. First, we observe that all individuals who receive and deserve benefits with Social Security also receive with the alternative

\footnotetext{
${ }^{18}$ We could have used the rate of awards (\# of applications / \# of awards), but with the information from the survey we only know if the individual receives a benefit but not if he has applied for and it has been denied. The economic interpretation for using the probability of receiving conditioned to deserving is that individuals with a high probability of deserving should receive a benefit.
} 
Table 8: Comparison between the Social Security and the screening mechanism.

\begin{tabular}{|c|c|c|}
\hline & Men & Women \\
\hline \multicolumn{3}{|l|}{ Social Security } \\
\hline * Total & 1333 & 429 \\
\hline${ }^{*}$ Receive and deserve ${ }^{a}$ & $487(36.53 \%)$ & $218(50.82 \%)$ \\
\hline${ }^{*}$ Receive but do not deserve ${ }^{b}$ & $846(63.47 \%)$ & $211(49.18 \%)$ \\
\hline \multicolumn{3}{|l|}{ Screening mechanism } \\
\hline * Total & 542 & 254 \\
\hline * Receive now, with SS and deserve & $487(89.85 \%)$ & $218(85.83 \%)$ \\
\hline * Receive now, with SS but do not deserve & $40(7.38 \%)$ & $25(9.84 \%)$ \\
\hline * Receive now, not with SS and deserve & $15(2.77 \%)$ & $11(4.33 \%)$ \\
\hline * Receive now, not with SS but do not deserve & 0 & 0 \\
\hline
\end{tabular}

mechanism. Second, the number of individuals who receive but do not deserve decrease from $63.46 \%$ to $7.38 \%$ for men and from $49.18 \%$ to $9.84 \%$ for women. Third, this mechanism does not assign benefits to any individual who does not deserve benefits. Finally there are $2.77 \%$ of men and $4.33 \%$ of women who deserve but do not receive according to Social Security. Unfortunately we do not know whether they have not applied for benefits or, conditional on applying, their application have been rejected. Finally, we have reduced the number of benefits by $58.89 \%$ for men and $49.18 \%$ for women.

From those individuals who receive but do not deserve, $82 \%$ declare to suffer disabilities for moving without way of transport, in public transport or in his own vehicle, but only $21.42 \%$ receives technical aids. This suggests that the improvement of facilities and reduction of architectural barriers could help in avoiding some of these situations.

The main lesson of this section is that administrative data should be regarded with some suspicion. This is so because applicants have incentives to misreport true disability status, but also because Provincial Departments of Social Security may have quantitative (or redistributive) targets regarding the placement of individuals.

We do not propose the disappearance of the whole bureaucracy of the Social Security, just because individuals could be tempted to misreport disabilities when answering the survey with the purpose of increasing the probability of deserving. In order to avoid these problems, we suggest several control measures over the applicant and the disability referees. For example, a medical team should visit the home and the working place of the applicant and study the way of displacement between both. Also random audits should be performed on medical judgements, conditioning examiner's wage earnings to the coincidence between his verdict and that of the auditor.

\section{Conclusions}

In this paper we partially audit the permanent disability awarding process in Spain in order to detect award errors, which can be assimilated in many cases (specially for those that are healthy), to benefit concessions due to economic reasons. In a preliminar but not less important 
step, we have designed up to six alternative deserving indicators using a very large number of self-reported disability measures from the DDHS survey. After choosing the best indicator on the basis of exogeneity and consistency criteria, we have estimated a latent variable bivariate econometric model for the decisions of receiving and deserving for those individuals who have developed contributive careers.

Disability benefits in many European countries are due to "truly" medical reason, to economic reason and/or the combination of these two factors. One of the objectives of this exercise is to tentatively distinguish between them. For example, those in sample receiving a disability benefits which do not have any disability can be classified as receiving a benefit dut to "economic reasons". Alternatively those receiving a benefit having some disabilities but of limited importance can be classified as receiving a benefit due to the combination of disabilities and economic reasons or policies.

After controlling for disabilities, limitations and other factors, we find that the individuals aged between 55 and 59, the self-employed or workers in the agricultural sector have a probability of receiving a benefit without deserving it significantly higher than the rest of individuals. This confirms that disability benefits have been used as a pathway to retirement for individuals below the early retirement age. Most likely the extension of the right to retire early (at age 60 at the time of the survey 1999 or before) may help in reducing the award error for this sector.

We have also shown that there are significant regional differences in the probability of receiving a benefit. This probability is higher in less developed Spanish regions: Asturias-Cantabria, Murcia, Andalucia and Extremadura. If we take into account that the awarding process depends on Social Security Provincial offices, it becomes clear that something abnormal is happening in the evaluation of the worker health status. The head of each Social Security Provincial Offices determines if a given applicant gets a pension of disability on the basis of the statement proposed by the Disability Evaluation Team. This statement indicates if there is a decrease or annulment of work capacity, if the above mentioned situation is constitutive of disability and in what degree. Therefore, the existence of award error implies either that the medical reports provided by the applicant were untrue, or that the classification statement elaborated by the Disability Evaluation Team is incorrect, or, most likely, that many disabilities in these regions are due to economic regions.

All these are elements of policy and with policy can be reduced. There are several policies that may help in reducing award errors. One possibility would be to carry out more diagnosis tests and explorations, although this would increase audit expenditures. For example, in the case of the osteoarticular pathologies in which pain plays a crucial role there is a trade off between the accomplishment of some expensive tests and the risk of paying undue pensions. We cannot forget the figure of revision due to improvement, worsening or misdiagnosis before 65 years old. This instrument eliminates the possibility of a life declaration without possibility of repeal. Nevertheless, it does not seem that revisions done up to the moment have settled the problem of award errors, since in the DDHS survey there are 2448 pensioners older than 65 years old, from which $1164(47.55 \%)$ have declared not to suffer any disability.

The Spanish Observatory of the Social Security has recently proposed several measures in order to improve the regulation of permanent disability benefits, preventing the access for the careers with insufficient contributions. First, the amount of the pension would be defined in terms of the benefit base and the quotation period (up to the moment the number of working years was not taken into account). Second, the approval of a list of occupational diseases with effect in permanent disability benefits. And finally, the exclusion of the permanent disability of those professions which technical requirements are unattainable for old-aged workers. In this case, it also proposes to modify retirement benefits relaxing the penalties for age.

Finally, we have designed a screening mechanism in which individuals receive a benefit if they have a sufficiently high deserving probability. With this mechanism the award error is signifi- 
cantly reduced. We do not propose in this paper to replace the Social Security awarding process by a computer procedure, but we emphasize that efficiency can be improved and expenditures in non-deserved benefits may be substantially reduced.

\section{References}

1. Anderson, K., Burkhauser, R., 1984. The importance of the measure of health in empirical estimates of the labor supply of older men. Economic Letters 16, 375-380.

2. Anderson, K., Burkhauser, R., 1985. The retirement-health nexus: a new measure of an old puzzle. Journal of Human Resources 20, 118-137.

3. Autor, D. H., Duggan , M. G., 2003. The rise in the disability rolls and the decline in unemployment. The Quarterly Journal of Economics 118, 157-205.

4. Baker, M., Stabile, M., Deri, C., 2004. What do self-reported, objective measures of health measure? Journal of Human Resources 39 1067-1093.

5. Barba Mora, A., 2001. Incapacidad permanente y Seguridad Social. Editorial Aranzadi.

6. Bazzoli, G., 1985. The early retirement decision: new empirical evidence on the influence of health. Journal of Human Resources 20, 214-234.

7. Berkovec, J., Stern, S., 1991. Job exit behavior of older men. Econometrica 59, 189-210.

8. Benítez-Silva, H., Buchinsky, M., Chan, H., Rust, J., Sheidvasser, S., 2004. How large is the bias in self-reported disability status? Journal of Applied Econometrics 19, 649-670.

9. Benítez-Silva, H., Buchinsky, M., Rust, J., 2005. How large are the classification errors in the Social Security Disability award process? NBER WP 10129.

10. Blau, D. M., Riphahn, R. T., 1999. Labor force transitions of older married couples in Germany. Labor Economics 6, 229-251.

11. Boldrin, M., S. Jiménez-Martín and F. Peracchi 1999. "Social Security and Retirement in Spain". In Gruber, J. and Wise, D. (eds.), Social Security Programs and Retirement around the World, Chicago University Press for the NBER.

12. Boskin, M., Hurd, M., 1978. The effect of Social Security on early retirement. Journal of Public Economics 10, 361-377.

13. Bound, J., 1989. The health and earnings of rejected disability insurance applicants. American Economic Review 79, 482-503.

14. Bound, J., 1991. Self reported versus objective measures of health in retirement models. Journal of Human Resources 26, 106-138.

15. Bound, J., Burkhauser, R. V., 1999. Economic analysis of transfer programs targeted on people with disabilities. In Ashenfelter, O., Card. D. (eds.), Handbook of Labor Economics, vol 3C, 3417-3528. Elsevier, Amsterdam.

16. Bound, J., Schoenbaum, M., Waidmann, T., 1995. Disability status and racial differences in the labour force attachment. Journal of Human Resources 30, 227-267.

17. Bound, J., Schoenbaum, M., Stinebrickner, T., 1998. Modeling the effect of health on retirement. National Bureau of Economic Research Summer Institute. 
18. Bound, J., Schoenbaum, M., Stinebrickner, T., Waidmann, T., 1999. The dynamic effects of health on the labor force transitions of older workers. Labour Economics 6, 179-202.

19. Bound, J., Waidmann, 1992. Disability tranfers, self-reported health and the labor force attachment of older men: evidence from the historical record. Quaterly Journal of Economics 107, 1393-1419.

20. Bukhauser, R., 1979. The pension acceptance decision of older worders. Journal of Human Resources 14, 63-75.

21. Chirikos, T., Nestel, G., 1984. Economic determinants and consequences of self-reported work disability. Journal of Health Economics 3, 117-136.

22. Dwyer, D., Mitchell, O., 1999. Health problems as determinants of retirement: are selfrated measures endogenous? Journal of Health Economics 18, 173-193.

23. Gordon, R., Blinder, A., 1980. Market wages, reservation wages and retirement decisions. Journal of Public Economics 14, 277-308.

24. Greene, W.H., 1993. Econometric analysis. Second Edition, Pretince Hall, New Yersey.

25. Gruber, J. and Wise, D. 1999 (eds) Social Security and Retirement across the World, Chicago University Press for the NBER.

26. Fabbri, D. Monfardini C. and Radice, R. 2005. "Style of practice and assortative mating: a recursive probit analysis of cesarean section scheduling in Italy" Department of Economics, University of Bologna. mimeo

27. Hanoch, G., Honig, M., 1983. Retirement, wages and labor supply of the elderly. Journal of Labor Economics 1, 131-151.

28. Haveman, R., de Jong, P., Wolfe, B., 1991. Disability transfers and the work decision of older men. Quarterly Journal of Economics 106, 131-161.

29. Haveman, R., Wolfe, B., 1984a. The decline in male labor force participation: comment. Journal of Political Economy 92, 532-541.

30. Haveman, R., Wolfe, B., 1984b. Disability transfers and early retirement: a causal relationship?. Journal of Public Economics 24, 47-66.

31. Heckman, J., 1978. Dummy endogenous variables in a simultaneous equation system. Econometrica 46, 931-959.

32. Jiménez-Martín, S., Labeaga, J.M. and Martínez-Granado, M., 1999. Working Paper WP 99-82, Universidad Carlos III de Madrid

33. Kerkhofs, M., Lindeboom, M., 1995. Subjective health measures and state department reporting errors. Health Economics 4, 221-235.

34. Kiefer, N., 1982. Testing for dependence in multivariate probit models. Biometrica 69, 161-166.

35. Kreider, B., 1999. Latent work disability and reporting bias. Journal of Human Resources 34, 734-769.

36. Leonard, J. S., 1979. The Social Security Disability program and labor force participation. National Bureau of Economic Research. Working Paper 392. 
37. Lumsdaine, R. L., Stock, J. H., Wise, D. A., 1997. Retirement incentives: the interaction between employer provided pension plans, Social Security and retiree health benefits. in M. Hurd and N. Yashiro,(eds.), The Economic Effects of Aging in the United States and Japan, University of Chicago Press.

38. Parsons, D., 1980. The decline in male labor force participation. Journal of Political Economy 88, 117-134.

39. Pérez Rueda, B., García Blázquez, M., García Blázquez Pérez, M., 2000. Fundamentos médico legales de la incapacidad laboral permanente. Editorial Comares, 4th edition.

40. Peracchi, F., Welch, F., 1994. Trends in labor force transitions of older men and women. Journal of Labor Economics 12, 210-242.

41. Rivers D, Vuong Q. 1988. "Limited information estimators and exogeneity tests for simultaneous probit models," Journal of Econometrics 39: 347-366.

42. Ruhm, C. J., 2000. Are recessions good for your health? Quarterly Journal of Economics, 617-650.

43. Ruhm, C. J., 2003. Good times make you sick. Journal of Health Economics 22, 637-658.

44. Slade, F., 1984. Older men: disability insurance and the incentive to work. Industrial Relations 23, 260-269.

45. Stern, S., 1989. Measuring the effect of disability on the labor force participation. Journal of Human Resources 24, 361-395.

46. Stewart, J. M., 2001. The impact of health status on the duration of unemployment spells and the implications for studies of the impact of unemployment on health status. Journal of Health Economics 20, 781-796.

47. Waidmann, T., Bound, J., Schoenbaum, M., 1995. The ilusion failure: trends in selfreported health in the U.S. elderly. Milbank Quaterly 73, 253-287.

48. Zabalza, A., Pissarides, P., Barton, M., 1980. Social Security and the choice between full-time work, part-time work and retirement. Journal of Public Economics 14, 245-276.

\section{Appendix}

\section{A. Disabilities, Deficiencies and Health Status Survey}

In 1986, the National Institute of Statistics (INE) performed a survey to detect the most important disabilities and deficiencies among the Spanish population according to the International Classification of Disabilities, Deficiencies and Impairments of the World Health Organization (WHO). This information has turned obsolete and it has been necessary to renew it. The Disabilities, Deficiencies and Health Status Survey [www.ine.es/prodyser/pubweb/discapa/discapamenu.htm] was aimed at identifying the actual situation of individuals with disabilities and was carried out by the Spanish statistical office during the second term of 1999. The main method to collect the information is personal interview to all the members of the selected household.

The survey is divided in three phases identified with the following questionnaires:

1. Household Questionnaire: collects socioeconomic information from all household members in order to establish differences between people with and without disabilities. 
2. Disabilities and Deficiencies Questionnaire: for people of 6 and more years who suffer at least one disability or deficiency. Individuals are required to enumerate all disabilities suffered according to a established classification of 36 disabilities and 27 deficiencies, indicating also the degree of severity, expected evolution, age when suffering the disability problem, deficiency that caused the disability, origin and duration. Finally, it also includes questions relating disabilities to changes in occupation and labor force status.

The D\&D questionnaire has two important limitations: the degree of disability for permanent disability pensioners, and the possible denial of an application for disability benefits are unknown. The former limitation prevent us from analyzing the rejection error.

3. Limitations and Impairments Questionnaire: for children with less than 6 years that suffer some limitation (not used for the purpose of the paper)

4. Health Questionnaire: selects randomly one member from each household no matter if he is affected or not by some disability (not used in the paper because the random nature of the sample reduces the number of available observations considerably)

This survey only gathers those disabilities that have affected or are expected to affect daily living activities for a period over a year. It is necessary to specify that certain disabilities produced by certain disfunctions (schizophrenia, depression, labyrinthine dizziness...) appear repeatedly in certain moments called crisis during life. An individual is considered to suffer one of these disabilities if the sum of the critical periods is larger than one year.

All disabilities are investigated even if they are overcome with the use of some technical help. It is important to specify that only are considered to be disabilities those that have been overcome with the use of technical external helps (crutches, wheels chair, prothesis of substitution of some member, auditory devices, probes, oxygen...), remaining excluded those that have been overcome by the use of technical internal helps (pacemaker, intraocular lenses, prothesis of knee, cardiac valves, cerebral valves of decompression...). An exception is done in case of vision disabilities, since we only take into account those that survive with the use of glasses or contact lenses.

For the definition of the six disability indicators, we have not included any reference to the use of technical help, because legislation establishes that each case must be studied separately, according to impairment, nature of the help and adaptation degree to it.

\section{B. Description of the variables}

\section{Classification of disabilities, severity and prognosis}

For each of the following 36 disabilities we define a binary variable that takes the value one if the individual declares to suffer this disability and the value zero in other case.

1. Seeing: (a)Receiving any image; (b) Global visual tasks; (c) Detailed visual tasks; (d) Other visual disabilities.

2. Hearing (a): Hearing any sound; (b) Hearing strong sounds; (c) Listening the speech.

3. Communicating: (a) Communicating through speech; (b) Communicating through alternative languages; (c) Communicating through not sealed gestures; (d) Communicating through conventional writing - reading.

4. Learning, applying knowledge and developing topics: (a) Recognizing persons/objects and being orientated in space and in time; (b) Remembering information and recent or past episodes; (c) Dealing and executing simple orders and/or doing simple tasks; (d) Dealing and executing complex orders and/or doing complex tasks. 
5. Moving: (a) Changes and maintenance of body positions; (b) Getting up and down and standing up; (c) Moving inside home.

6. Using arms and hands: (a) Moving/transporting not very heavy objects; (b) Using utensils and tools; (c) Manipulating small objects with hands and fingers.

7. Moving out of home: (a) Moving without way of transport; (b) Moving in public transport; (c) Driving own vehicle.

8. Looking after oneself: (a) Washing oneself; (b) Controlling physical needs; (c) Dressing and undressing; (d) Eating and drinking;

9. Houseworking: (a) Do the shopping; (b) Cooking; (c) Washing and ironing clothes; (d) Cleaning the house; (e) Looking after the well-being of the family.

10. Relating to people: (a) Supporting relations of fondness with close relatives; (b) Doing friends; (c) Relating to companions, chiefs and subordinates;

Classification of the variable severity Classification of variable prognosis

1. Without any difficulty

2. With moderate difficulty

1. Recoverable

3. With serious difficulty

2. Recoverable with restrictions

4. Can not do the activity

3. Stable without perspectives of improvement

4. Can go worse

5. It is not possible to determine it.

\section{Classification of the deficiencies}

We group the following 27 deficiencies in 8 categories:

1. Mental deficiencies: (a) Insanity; (b) Other mental illnesses.

2. Visual deficiencies: (a) Total blindness; (b) Bad vision.

3. Hearing deficiencies: (a) Deafness before speaking; (b) Deafness after speaking; (c) Bad hearing; (d) Disfunction of the balance.

4. Deficiencies of the language, speech and voice: (a) Muteness (not because of deafness); (b) Difficult or incomprehensible speech.

5. Osteoarticular deficiencies: (a) Head; (b) Vertebral column; (c) Upper extremities; (d) Low extremities.

6. Deficiencies of the nervous system: (a) Paralysis of an upper extremity; (b) Paralysis of a low extremity; (c) Paraplegia; (d) Tetraplegia; (e) Dysfunction of the coordination of movements; (f) Other deficiencies of the nervous system.

7. Visceral deficiencies: (a) Respiratory device; (b) Cardiovascular device; (c) Digestive device; (d) Genital-urinary device; (e) Endocrine-metabolic device; (f) Hematopoietic device and immunitary system.

8. Other deficiencies: (a) Skin.

\section{Classification of the problem that caused the deficiency}
1. Congenital
6. Labor accident
2. Problems in the childbirth
7. Another type of accident
3. Traffic accident
8. Common disease
4. Domestic accident
9. Occupational disease
5. Leisure accident
10. Other reasons 


\title{
Description of the variables of the bivariate probit model
}

\section{* Disabilities and deficiencies:}

We have defined a binary variable that takes the value one if the individual suffers one of the following disabilities or deficiencies.:

- Deficiencies: (1) Vertebral column; (2) Upper and low extremities.

- Disabilities: (1) Seeing; (2) Hearing; (3) Communicating; (4) Remembering; (5) Executing orders; (6) Maintaining body postures; (7) Moving inside home; (8) Using hands and fingers; (9) Moving outside home; (10) Taking care of oneself; (11) Houseworking; (12) Relating.

We have only included deficiencies referred to vertebral column and upper and low extremities because given the definitions of the survey, a deficiency is the pathological cause of a disability, it seems reasonable that an individual with disability for global visual tasks is also going to declare bad vision, or an individual with paralysis of a low extremity is going to answer disability for moving inside home and using public transport. Hence, to avoid unnecessary duplicities we have omitted most of the deficiencies in the bivariate probit model. Besides that, what really matters for permanent disability is not the name of the illness but the repercussion on labor capacity.

In fact, osteoarticular deficiencies are the most important ones. In fact, $56.03 \%$ of individuals receiving a benefit $(22.43 \%$ men and $33.60 \%$ women) suffer vertebral column problems, $29.46 \%$ (12.66\% men and $16.80 \%$ women) are affected by upper extremities deficiencies and $37.69 \%(16.89 \%$ men and $20.80 \%)$ by low extremities pathologies. This deficiencies are also declared by many individuals who receive a benefit but do not deserve it. (See Tables C.2 and C.3).

\section{* Socioeconomic variables}

$\begin{array}{ll}\text { Age between 55-59 } & 1 \text { if age is between } 55 \text { and } 59 \\ \text { Married } & 1 \text { if he/she is married } \\ \text { Spouse working } & 1 \text { if spouse is working } \\ \text { Spouse disability benefit } & 1 \text { if spouse receives a disability benefit } \\ \text { Household main breadwinner } & 1 \text { if he/she is the household main breadwinner }\end{array}$

\section{* Health variables}

Caretaker

Impairment certificate

Rehabilitation treatment

Change of house
1 if he/she needs somebody to take care of him/her

1 if he/has has received an impairment certificate

1 if he/she has finished a rehabilitation treatment

1 if he/she has moved because of a disability

\section{* Level of Education}

$\begin{array}{ll}\text { Without studies } & \text { (omitted category) } \\ \text { Elementary } & 1 \text { if he/she has only finished elementary education } \\ \text { High School } & 1 \text { if he/she has only finished high school or vocational training } \\ \text { College } & 1 \text { if he/she is a graduate or bachelor }\end{array}$

\section{* Relation with economic activity}

The omitted category for active is "inactive" and for unemployed is "working". If individual is receiving now a disability benefit, the dummy unemployed takes the value one if that was relation with economic activity before becoming pensioner.

Active $\quad 1$ if he/she is active (working or unemployed)

Unemployed 1 if he/she is unemployed but has already worked

\author{
* Skill level: \\ The omitted category is "Unskilled"
}




$\begin{array}{ll}\text { White collar } & \begin{array}{l}1 \text { if management, public administration, white collars workers, } \\ \text { and intellectuals }\end{array} \\ \text { Skilled } & \begin{array}{l}1 \text { if he/she is a qualified worker in agriculture, cattle raising, } \\ \text { fishing, industry, mining industry, construction, services }\end{array}\end{array}$

\section{* Sector of occupation:}

The omitted category is "family helper".

$$
\begin{array}{ll}
\text { Self-employer } & 1 \text { if he/she is a self-employer } \\
\text { Public sector } & 1 \text { if he/she is working at the public sector } \\
\text { Private sector } & 1 \text { if he/she is working at the private sector }
\end{array}
$$

* Activity sector: we have defined a binary variable for each sector (agriculture/ cattle raising/ fishing, industry, construction and services).

* Place of residence: we have defined a binary variable for each of the 19 Spanish regions. However, due to the small sample size for some communities we have grouped Ceuta and Melilla with Andalucía, Navarra and Rioja with Aragón and Asturias with Cantabria.

\begin{tabular}{|c|c|c|c|c|c|c|c|c|c|}
\hline & \multicolumn{8}{|c|}{ Ratio disability to retirement benefits } & \multirow{2}{*}{$\begin{array}{r}\text { GDPpc } \\
1998 \\
\end{array}$} \\
\hline & 1985 & 1988 & 1991 & 1994 & 1997 & 1998 & 2000 & 2002 & \\
\hline Andalucía & 91.9 & 93.3 & 88.6 & 84.6 & 76.5 & 27.3 & 27.0 & 26.4 & 56.1 \\
\hline Aragón & 42.1 & 40.7 & 38.6 & 38.0 & 34.0 & 13.6 & 13.2 & 13.1 & 89.0 \\
\hline Asturias & 56.4 & 54.3 & 51.6 & 50.6 & 45.7 & 18.7 & 18.5 & 18.9 & 66.9 \\
\hline Baleares & 42.3 & 41.8 & 42.8 & 45.0 & 43.4 & 19.2 & 20.0 & 20.6 & 118.7 \\
\hline Canarias & 74.6 & 74.6 & 73.2 & 67.0 & 58.5 & 23.8 & 22.3 & 21.7 & 78.6 \\
\hline Cantabria & 43.9 & 43.9 & 43.7 & 43.0 & 39.3 & 15.2 & 15.0 & 15.1 & 74.2 \\
\hline Castilla La M & 52.9 & 51.9 & 48.7 & 45.8 & 40.3 & 14.2 & 14.1 & 14.3 & 64.5 \\
\hline Castilla León & 54.2 & 52.4 & 48.3 & 45.5 & 39.1 & 13.4 & 12.5 & 11.9 & 73.6 \\
\hline Cataluña & 57.2 & 56.8 & 53.5 & 49.2 & 43.4 & 18.7 & 17.9 & 17.1 & 101.4 \\
\hline Extremadura & 56.6 & 57.5 & 55.8 & 53.4 & 47.7 & 18.1 & 16.9 & 16.4 & 55.4 \\
\hline Galicia & 55.2 & 55.6 & 54.3 & 51.9 & 45.1 & 14.2 & 13.7 & 13.4 & 67.9 \\
\hline Madrid & 40.2 & 35.4 & 37.5 & 35.6 & 31.0 & 14.2 & 13.2 & 12.6 & 109.2 \\
\hline Murcia & 150.4 & 155.8 & 152.0 & 142.3 & 116.4 & 29.8 & 26.9 & 25.2 & 66.3 \\
\hline Navarra & 52.1 & 49.7 & 46.4 & 44.3 & 39.4 & 16.6 & 16.0 & 15.9 & 98.5 \\
\hline País Vasco & 47.8 & 45.3 & 43.1 & 41.0 & 37.0 & 17.6 & 16.6 & 15.8 & 90.3 \\
\hline La Rioja & 65.9 & 64.4 & 60.4 & 58.5 & 50.2 & 18.0 & 17.0 & 16.1 & 96.2 \\
\hline Comunidad Val. & 52.7 & 49.9 & 45.7 & 42.2 & 38.9 & 16.7 & 16.5 & 16.7 & 82.8 \\
\hline Ceuta & 83.3 & 70.0 & 63.6 & 50.0 & 44.8 & 19.4 & 19.4 & 18.1 & 61.7 \\
\hline Melilla & 100.0 & 94.1 & 88.9 & 90.0 & 90.5 & 33.3 & 33.3 & 32.3 & 64.7 \\
\hline España & 59.1 & 57.5 & 55.2 & 52.2 & 46.4 & 18.3 & 17.6 & 17.2 & 81.5 \\
\hline
\end{tabular}

\section{Descriptive Tables}

Table C.1. Ratio permanent disability benefits to retirement benefits

Notes: GDPpc: Gross GDP per capita (EU15=100); Since 1998 (Law 24/1997) disability benefits for individuals aged $65+$ are counted as retirement benefits. Sources: Ministry of Labor and Social Issues and FBBVA. 
Table C.2. Prevalence of Disabilities and deficiencies.

$\mathrm{N}$

Disability for:

Seeing

Hearing

Communicating

Learning, applying knowledge

Moving

Using arms and hands

Moving outside home

Looking after oneself

Houseworking

Relating to people

Deficiency for:

Mental deficiencies

Visual deficiencies

Hearing deficiencies

Deficiencies of the language

Osteoarticular deficiencies

Deficiencies nervous system

Visceral deficiencies

Other deficiencies

\begin{tabular}{|r|r|r|r|r|r|r|r|}
\hline \multicolumn{2}{|c|}{ Men } & \multicolumn{2}{c|}{ Women } & \multicolumn{2}{c|}{ Men w benefits } & \multicolumn{2}{c|}{ Women w benefits } \\
\hline Deserve & Not Des & Deserve & Not Des & Deserve & Not Des & Deserve & Not Des \\
\hline 709 & 275 & 440 & 112 & 306 & 73 & 111 & 25 \\
\hline
\end{tabular}

\begin{tabular}{|r|r|r|r|r|r|r|r|}
\hline 22.43 & 22.55 & 22.95 & 14.29 & 20.92 & 15.07 & 24.32 & 21.43 \\
22.99 & 28.00 & 18.86 & 30.36 & 11.44 & 10.96 & 9.01 & 0 \\
12.41 & 3.64 & 8.64 & 2.68 & 14.71 & 6.85 & 9.91 & 7.14 \\
10.58 & 0.73 & 9.32 & 1.79 & 12.42 & 0 & 9.91 & 0 \\
32.44 & 18.91 & 41.82 & 25.00 & 40.52 & 30.14 & 45.95 & 14.29 \\
33.99 & 23.18 & 43.64 & 28.57 & 46.41 & 36.99 & 48.65 & 42.86 \\
55.15 & 28.00 & 54.32 & 22.32 & 69.28 & 41.10 & 61.26 & 21.43 \\
15.66 & 4.00 & 15.23 & 4.46 & 20.92 & 8.22 & 22.52 & 0 \\
20.31 & 7.64 & 44.32 & 20.54 & 29.41 & 19.18 & 56.76 & 28.57 \\
10.30 & 1.82 & 11.36 & 4.46 & 12.41 & 2.74 & 13.51 & 7.14 \\
\hline \multicolumn{7}{|c|}{} \\
\hline 9.45 & 1.45 & 9.77 & 7.14 & 14.38 & 2.74 & 13.51 & 21.43 \\
20.31 & 21.09 & 20.91 & 13.39 & 18.30 & 9.59 & 21.62 & 14.29 \\
22.28 & 27.64 & 18.18 & 29.46 & 10.78 & 10.96 & 9.01 & 0 \\
2.40 & 1.09 & 1.59 & 0.89 & 2.94 & 1.37 & 1.80 & 7.14 \\
39.49 & 36.36 & 54.55 & 32.12 & 44.44 & 53.42 & 63.06 & 28.57 \\
10.58 & 3.64 & 9.77 & 5.36 & 16.67 & 5.48 & 11.71 & 7.14 \\
11.99 & 8.36 & 8.41 & 8.93 & 19.93 & 15.07 & 9.01 & 21.43 \\
0.14 & 0.36 & 0.45 & 0 & 0.33 & 0 & 0.9 & 0 \\
\hline
\end{tabular}

Table C.4. Socioeconomic characteristics

\begin{tabular}{|l|r|r|r|r|}
\multicolumn{1}{c|}{} & \multicolumn{2}{|c|}{ Men } & \multicolumn{2}{c|}{ Women } \\
\cline { 2 - 5 } & Receive & $\begin{array}{c}\text { Receive } \\
\text { Deserve }\end{array}$ & Receive & \multicolumn{2}{c|}{ Receive } \\
Net deserve & Deserve & Not deserve \\
\hline Rehabilitation treatment & 7.30 & 0 & 18.11 & 0 \\
Change of house because of disability & 30.25 & 28.38 & 35.43 & 35.29 \\
Married & 7.62 & 6.76 & 10.24 & 11.76 \\
Spouse is working & 80.72 & 83.56 & 64.86 & 50 \\
Main breadwinner & 15.14 & 6.71 & 29.53 & 9.06 \\
Age between 55-59 & 84.97 & 90.41 & 27.03 & 35.71 \\
Education & 47.06 & 35.62 & 47.75 & 28.57 \\
*Without elementary & & & & \\
*Elementary & 31.05 & 32.77 & 35.13 & 28.57 \\
*High School & 46.73 & 43.94 & 40.54 & 35.71 \\
*College & 18.63 & 20.55 & 15.32 & 21.43 \\
Professional occupation (before DB) & 3.59 & 2.74 & 9.01 & 14.29 \\
*Unskilled & & & & \\
*Skilled & 22.14 & 18.84 & 52.25 & 42.87 \\
*White collar & 65.44 & 72.46 & 40.54 & 35.71 \\
\hline
\end{tabular}


Table C.5. Spouse labor force status

\begin{tabular}{|c|c|c|c|c|c|c|}
\hline & \multirow{2}{*}{\multicolumn{3}{|c|}{ Men }} & \multirow{2}{*}{\multicolumn{3}{|c|}{ Women }} \\
\hline & & & & & & \\
\hline & \multirow{2}{*}{$\begin{array}{c}\text { Without } \\
\text { DB }\end{array}$} & \multicolumn{2}{|c|}{ With DB } & \multirow{2}{*}{$\begin{array}{c}\text { Without } \\
\text { DB }\end{array}$} & \multicolumn{2}{|c|}{ Without DB } \\
\hline & & Deserve & Not deserve & & Deserve & Not deserve \\
\hline Working & 27.66 & 22.66 & 13.11 & 58.19 & 48.75 & 25 \\
\hline Working but temporary absent & 0.58 & 1.17 & & 1.74 & & \\
\hline Looking for first job & 0.39 & 0.78 & 1.64 & 0.35 & & \\
\hline Unemployed (has worked before) & 5.61 & 7.42 & 6.56 & 13.59 & 13.75 & \\
\hline Unable for working & 0.77 & 1.95 & 3.28 & 3.83 & 6.25 & \\
\hline Contributive Disability Benefit (DB) & 1.74 & 3.91 & 6.56 & 9.06 & 15 & 37.5 \\
\hline Not Contributive Disability Benefit & 2.9 & 2.34 & 3.28 & 0.7 & & \\
\hline Retirement Benefit & 0.77 & 1.17 & & 11.15 & 16.25 & 12.5 \\
\hline Studying & 0.39 & 0.78 & & & & \\
\hline Houseworking & 58.41 & 57.42 & 63.96 & & & \\
\hline Other situations & 0.77 & 0.39 & 1.64 & 1.39 & & 25 \\
\hline
\end{tabular}

Men $(\mathrm{N}=984) 82.43 \%$ of the sample is married; Women $(\mathrm{N}=552) 65.28 \%$ of the sample is married 
D. Estimations and forecasts

Table D.1. Bivariate probit. Sample with disabilities (sample B1)

\begin{tabular}{|c|c|c|c|c|c|c|c|c|}
\hline & \multicolumn{4}{|c|}{ Men } & \multicolumn{4}{|c|}{ Women } \\
\hline & \multicolumn{2}{|c|}{ Deserve } & \multicolumn{2}{|c|}{ Receive } & \multicolumn{2}{|c|}{ Deserve } & \multicolumn{2}{|c|}{ Receive } \\
\hline & Coef. & $\mathrm{t}$ & Coef. & $\mathrm{t}$ & Coef. & $\mathrm{t}$ & Coef. & $\mathrm{t}$ \\
\hline Constant & -0.8056 & 3.50 & -0.9608 & -3.20 & -0.8503 & -2.20 & -0.9293 & -2.68 \\
\hline \multicolumn{9}{|l|}{ Disability } \\
\hline Vertebral column & 0.4186 & 2.14 & 0.3044 & 2.02 & 0.7184 & 3.48 & 0.1936 & 2.08 \\
\hline Upper and low extremities & 0.0552 & 2.27 & 0.2642 & 2.50 & 0.4462 & 1.82 & 0.0813 & 2.39 \\
\hline Seeing & 0.3658 & 2.27 & 0.0253 & 2.17 & 0.9053 & 4.01 & 0.0346 & 2.20 \\
\hline Hearing & 0.3194 & 1.93 & 0.3654 & 3.54 & 0.4573 & 2.13 & 0.6298 & 2.84 \\
\hline Communicating & 0.2465 & 2.00 & 0.4685 & 2.01 & 0.7546 & 2.75 & 0.8165 & 2.45 \\
\hline Remembering & 0.2852 & 2.37 & 0.3842 & 2.95 & 0.3427 & 2.59 & 0.2613 & 2.59 \\
\hline Executing orders & 0.3134 & 1.90 & 0.2885 & 2.80 & 0.1950 & 2.19 & 1.1224 & 1.93 \\
\hline Maintaining body postures & 0.2282 & 2.05 & 0.0316 & 2.16 & 0.0706 & 3.30 & 0.2068 & 1.99 \\
\hline Moving inside home & 0.4744 & 2.41 & 0.0295 & 2.17 & 0.0291 & 3.13 & 0.1602 & 2.80 \\
\hline Using hands and fingers & 0.2162 & 2.49 & 0.2821 & 2.19 & 0.3649 & 2.14 & 0.1926 & 2.24 \\
\hline Moving outside home & 0.4109 & 2.87 & 0.3889 & 3.63 & 0.6666 & 3.72 & 0.1091 & 2.65 \\
\hline Taking care of oneself & 0.5355 & 2.19 & 0.1974 & 3.10 & 0.0938 & 2.31 & 0.1865 & 2.36 \\
\hline Houseworking & 0.0405 & 2.18 & 0.5447 & 2.95 & 0.3401 & 1.83 & 0.4302 & 2.48 \\
\hline Relating & 0.8202 & 2.38 & 0.5579 & 2.93 & 0.5068 & 2.30 & 0.1732 & 3.05 \\
\hline \multicolumn{9}{|l|}{ Socioeconomic characteristics } \\
\hline Age between $55-59$ & 0.0733 & 2.64 & 0.1379 & 2.21 & 0.2069 & 2.35 & 0.1332 & 2.90 \\
\hline Change of house & 0.3917 & 2.11 & 0.6247 & 2.18 & 0.0516 & 2.15 & 0.5162 & 1.91 \\
\hline Impairment certificate & 0.1240 & 2.91 & 0.7150 & 5.77 & 0.2575 & 2.41 & 0.5962 & 3.76 \\
\hline Needs caretaker & 0.7702 & 2.38 & 0.1811 & 2.60 & 0.2694 & 2.93 & 0.3602 & 2.20 \\
\hline Rehabilitation treatment & 0.1286 & 2.81 & 0.2731 & 1.92 & 0.0582 & 2.34 & 0.0366 & 2.24 \\
\hline Spouse working & -0.0191 & 1.52 & -0.4148 & -2.82 & 0.0038 & 1.18 & -0.1079 & -2.13 \\
\hline Spouse disability benefit & 0.0189 & 1.75 & 0.3089 & 2.67 & 0.0058 & 1.69 & 0.1699 & 2.55 \\
\hline Married & 0.0249 & 0.63 & 0.0988 & 2.01 & 0.0105 & 0.71 & 0.0141 & 1.98 \\
\hline Elementary & 0.8045 & 2.09 & 1.6779 & 1.96 & 0.3394 & 2.63 & 0.9641 & 2.51 \\
\hline High School & 0.5977 & 2.23 & 0.6317 & 2.05 & 0.0300 & 2.39 & -0.1359 & -2.88 \\
\hline College & 0.2952 & 2.05 & 0.3559 & 2.42 & -0.0893 & -2.27 & -0.6535 & -2.02 \\
\hline Active & 0.1841 & 2.01 & 0.3195 & -1.90 & -0.0569 & -2.24 & 0.2020 & 2.03 \\
\hline Unemployed & -0.4425 & -2.93 & -0.2975 & -2.14 & 0.1578 & 2.62 & -1.4187 & -3.09 \\
\hline Main breadwinner & -0.1978 & -0.96 & 0.0860 & 2.43 & 0.0243 & 1.11 & 0.1554 & 2.67 \\
\hline White collar & -0.1316 & -2.60 & 0.1696 & 3.43 & 0.1917 & 2.77 & 0.8429 & 3.42 \\
\hline Skilled worker & -0.0175 & 3.34 & 0.7779 & 5.13 & 0.3394 & 1.94 & 0.9641 & 4.00 \\
\hline \multicolumn{9}{|l|}{ Regions (Murcia omitted) } \\
\hline Andalucía-Ceuta-Melilla & 0.7624 & 1.39 & -0.0073 & -1.99 & 0.5326 & 1.17 & -0.1275 & -2.08 \\
\hline Aragón-Navarra-Rioja & 0.7546 & 1.60 & -0.2636 & -1.99 & 0.5235 & 1.21 & -0.4570 & -1.89 \\
\hline Asturias-Cantabria & 1.0826 & 1.18 & -1.0627 & -2.22 & 0.2898 & 0.76 & -0.5114 & -2.46 \\
\hline Baleares & 0.7349 & 1.12 & -1.0076 & -2.02 & 0.2621 & 0.61 & -0.1546 & -2.54 \\
\hline Canarias & 0.4906 & 0.96 & -1.0566 & -1.91 & 0.5562 & 1.32 & -0.6078 & -2.31 \\
\hline Castilla La Mancha & 0.9363 & 0.86 & -0.9415 & -3.19 & 0.2946 & 0.80 & -0.3446 & 1.97 \\
\hline Castilla León & 0.5839 & 1.35 & -0.8752 & -2.04 & 0.3379 & 1.16 & -0.5008 & -1.84 \\
\hline Cataluña & 0.6279 & 1.41 & -0.2638 & -2.29 & 0.5208 & 1.35 & -0.4553 & -2.06 \\
\hline Extremadura & 1.1119 & 1.01 & -0.0242 & -1.90 & 0.8071 & 1.38 & -0.2529 & -1.87 \\
\hline Galicia & 0.4978 & 1.13 & -0.3957 & -1.99 & 0.2577 & 0.49 & -0.4569 & -2.26 \\
\hline Madrid & 1.0609 & 1.06 & -0.9277 & -2.08 & 0.4127 & 1.18 & -0.6261 & -2.78 \\
\hline País Vasco & 0.05818 & 1.24 & -0.8396 & -2.87 & 0.0953 & 0.23 & -0.7922 & -2.46 \\
\hline Comunidad Valenciana & 0.3563 & 0.75 & -0.5315 & -1.84 & 0.3380 & 1.11 & -0.4381 & -2.54 \\
\hline $\mathrm{N}$ & & & & 984 & & & & 552 \\
\hline Rho & & & & 0.3690 & & & & 0.3161 \\
\hline Log likelihood & & & & 2.3350 & & & & 0.4645 \\
\hline
\end{tabular}


Table D.2. Marginal probabilities. Men with disabilities

\begin{tabular}{|c|c|c|c|c|c|}
\hline & $\begin{array}{c}\text { Deserving } \\
\text { (1) }\end{array}$ & $\begin{array}{c}\% \text { to } \\
\text { Baseline }\end{array}$ & $\begin{array}{l}\text { Receiving } \\
(2)\end{array}$ & $\begin{array}{c}\% \text { to } \\
\text { Baseline }\end{array}$ & $(1)-(2) /(1)$ \\
\hline Baseline (BL) & 0.3235 & & 0.4539 & & -0.4031 \\
\hline \multicolumn{6}{|l|}{ Disability } \\
\hline Vertebral column & 0.4843 & 47.91 & 0.5748 & 26.63 & -0.1868 \\
\hline Upper and low extremities & 0.3437 & 6.24 & 0.5589 & 23.13 & -1.5261 \\
\hline Seeing & 0.4633 & 43.21 & 0.4639 & 2.20 & -0.0013 \\
\hline Hearing & 0.4449 & 37.53 & 0.5985 & 31.86 & -0.3446 \\
\hline Communicating & 0.4163 & 28.69 & 0.6378 & 40.52 & -0.5321 \\
\hline Remembering & 0.4314 & 33.35 & 0.6058 & 33.47 & -0.4043 \\
\hline Executing orders & 0.4426 & 31.68 & 0.5685 & 25.25 & -0.2845 \\
\hline Maintaining body postures & 0.4092 & 26.49 & 0.4664 & 2.75 & -0.1398 \\
\hline Moving inside home & 0.5066 & 56.60 & 0.4656 & 2.58 & 0.0809 \\
\hline Using hands and fingers & 0.4045 & 25.04 & 0.5660 & 24.70 & -0.3993 \\
\hline Moving outside home & 0.4813 & 48.78 & 0.6076 & 33.86 & -0.2624 \\
\hline Taking care of oneself & 0.5309 & 64.11 & 0.5325 & 17.31 & -0.0030 \\
\hline Houseworking & 0.3382 & 4.54 & 0.6659 & 46.71 & -0.9689 \\
\hline Relating & 0.6414 & 98.26 & 0.6708 & 47.79 & -0.0458 \\
\hline \multicolumn{6}{|l|}{ Socioeconomic characteristics } \\
\hline Age between 55-59 & 0.3503 & 8.28 & 0.5088 & 12.09 & -0.4502 \\
\hline Change of house & 0.4736 & 46.40 & 0.6946 & 53.03 & -0.4666 \\
\hline Impairment certificate & 0.3692 & 14.12 & 0.7255 & 59.84 & -0.9643 \\
\hline Needs caretaker & 0.6226 & 92.46 & 0.5259 & 15.82 & 0.1552 \\
\hline Rehabilitation treatment & 0.3710 & 14.68 & 0.5518 & 25.57 & -0.4873 \\
\hline Spouse working & 0.3256 & 0.65 & 0.3329 & -28.87 & 0.0083 \\
\hline Spouse disability benefit & 0.3394 & 4.91 & 0.6148 & 35.46 & -0.8114 \\
\hline Married & 0.3325 & 2.79 & 0.4932 & 8.65 & -0.4833 \\
\hline Elementary and unskilled & 0.6244 & 93.01 & 0.8829 & 94.51 & -0.4139 \\
\hline High School and skilled & 0.4838 & 49.55 & 0.7951 & 75.24 & -0.6434 \\
\hline High School and white collar & 0.4832 & 49.36 & 0.7847 & 72.92 & -0.6239 \\
\hline College and skilled & 0.3654 & 12.95 & 0.6958 & 53.29 & -0.9042 \\
\hline Main breadwinner & 0.2560 & -20.86 & 0.4881 & 7.53 & -0.9066 \\
\hline Unemployed & 0.4933 & 52.49 & 0.3396 & -25.18 & 0.3116 \\
\hline \multicolumn{6}{|l|}{ Regions (Murcia omitted) } \\
\hline Andalucía-Ceuta-Melilla & 0.6197 & 91.56 & 0.4509 & -0.66 & 0.2724 \\
\hline Aragón-Navarra-Rioja & 0.6167 & 96.63 & 0.3521 & -24.43 & 0.4298 \\
\hline Asturias-Cantabria & 0.7339 & 126.86 & 0.1193 & -73.72 & 0.8374 \\
\hline Baleares & 0.6091 & 88.28 & 0.1306 & -71.23 & 0.7856 \\
\hline Canarias & 0.5528 & 70.88 & 0.1205 & -73.45 & 0.7828 \\
\hline Castilla La Mancha & 0.6838 & 111.37 & 0.1452 & -68.01 & 0.7145 \\
\hline Castilla Léon & 0.5502 & 70.07 & 0.1608 & -64.57 & 0.7077 \\
\hline Cataluña & 0.5675 & 66.15 & 0.3521 & -22.43 & 0.3796 \\
\hline Extremadura & 0.7434 & 129.79 & 0.4443 & -2.11 & 0.4023 \\
\hline Galicia & 0.5160 & 59.50 & 0.3044 & -32.94 & 0.4185 \\
\hline Madrid & 0.7267 & 124.64 & 0.1483 & -67.33 & 0.7959 \\
\hline País Vasco & 0.5493 & 69.79 & 0.1697 & -62.61 & 0.6911 \\
\hline Comunidad Valenciana & 0.4595 & 42.04 & 0.2586 & -43.03 & 0.4372 \\
\hline
\end{tabular}

BL: male, below 55, single, college, white collar, living in Murcia, with moderate disabilities, without rehabilitation treatment, impairment certificate, caretaker and has not changed house because of disability. 
Table D.3. Probability of receiving being healthy (sample B0 $)^{a}$

Constant
Age 50-54
Age 55-59
Married
Main breadwinner
Elementary
High School
College
Andalucia-Ceuta-Melilla
Aragon-Navarrra-Rioja
Baleares
Canarias
C. La Mancha
C. León
Cataluña
Extremadura
Galicia
Madrid
Murcia
País Vasco
C. Valenciana
N
Log Likelihood
pseudo $R^{2}$

\begin{tabular}{cc|cc}
\hline \multicolumn{2}{c|}{ Men } & \multicolumn{2}{c}{ Women } \\
\hline Coef. & $\mathrm{t}$ & Coef. & $\mathrm{t}$ \\
\hline-1.021 & -9.73 & -1.524 & -8.19 \\
0.141 & 3.00 & 0.079 & 0.96 \\
0.448 & 9.72 & 0.384 & 4.74 \\
-0.155 & -2.78 & -0.220 & -2.38 \\
-0.287 & -4.69 & -0.013 & -0.14 \\
-0.208 & -4.29 & -0.299 & -3.39 \\
-0.479 & -8.00 & -0.506 & -4.82 \\
-0.733 & -9.80 & -0.635 & -5.44 \\
-0.110 & -1.30 & 0.081 & 0.51 \\
-0.199 & -2.05 & -0.062 & -0.34 \\
-0.268 & -1.90 & -0.204 & -0.79 \\
-0.457 & -3.61 & -0.796 & -2.26 \\
-0.298 & -2.82 & -0.144 & -0.68 \\
-0.280 & -3.07 & -0.228 & -1.26 \\
-0.347 & -3.66 & 0.078 & 0.48 \\
-0.204 & -1.67 & -0.406 & -1.28 \\
-0.268 & -2.75 & -0.284 & -1.54 \\
-0.459 & -4.11 & -0.348 & -1.64 \\
-0.275 & -2.04 & 0.077 & 0.35 \\
-0.340 & -2.98 & -0.090 & -0.45 \\
-0.214 & -2.14 & -0.075 & -0.41 \\
\hline & 16980 & \multicolumn{2}{c}{-7491} \\
-2708.02 & & -791.95 \\
0.0668 & & 0.0704
\end{tabular}

${ }^{a}$ Omitted categories: age 45-49, no education and living in Asturias or Cantabria.

Table D.4. Marginal probability of receiving being healthy (sample B0) ${ }^{a}$

\begin{tabular}{lrrr|rrr} 
& \multicolumn{3}{c|}{ Men } & \multicolumn{3}{c}{ Women } \\
\cline { 2 - 7 } Baseline & $45-49$ & $50-54$ & $55-59$ & $45-49$ & $50-54$ & $55-59$ \\
\cline { 2 - 7 } Living in Madrid & .1536 & .1894 & .2832 & .0637 & .0742 & .1271 \\
Married & .0694 & .0902 & .1509 & .0306 & .0365 & .0684 \\
Main breadwinner & .1198 & .1504 & .2333 & .0405 & .0479 & .0869 \\
Elementary & .1094 & .1216 & .1948 & .0621 & .0724 & .1244 \\
Secondary & .0668 & .0870 & .2172 & .0341 & .0405 & .0750 \\
College & .0397 & .0534 & .0958 & .0212 & .0255 & .0499 \\
& & & & .0154 & .0187 & .0379
\end{tabular}

${ }^{a}$ Baseline: single, no breadwinner, high school education and living in Asturias or Cantabria. 